\title{
Nonlinear Aeroelastic Modeling and Analysis of Fully Flexible Aircraft
}

\author{
Carlos E. S. Cesnik ${ }^{*}$ and Weihua $\mathrm{Su}^{\dagger}$ \\ The University of Michigan, Ann Arbor, MI, 48109-2140
}

\begin{abstract}
This paper introduces an approach to effectively model the nonlinear aeroelastic behavior of fully flexible aircraft. The study is conducted based on a nonlinear strainedbased finite element framework in which the developed low-order formulation captures the nonlinear (large) deflection behavior of the wings, and the unsteady subsonic aerodynamic forces acting on them. Instead of merely considering the nonlinearity of the wings, the paper will allow all members of the vehicle to be flexible. Due to their characteristics of being long and slender structures, the wings, tail, and fuselage of highly flexible aircraft can be modeled as beams undergoing three dimensional displacements and rotations. The cross-sectional stiffness and inertia properties of the beams are calculated along the span, and then incorporated into the 1-D nonlinear beam model. Finite-state unsteady subsonic aerodynamic loads are incorporated to be coupled with all lifting surfaces, so as to complete the state space aeroelastic model. Different Sensorcraft concepts are modeled and studied, including conventional single-wing and joined-wing aircraft configurations with flexible fuselage and tail. Based on the proposed models, roll responses and stabilities are studied and compared with linearized and rigidized models. At last, effects of the flexibility of the fuselage and tail on the roll maneuver and stability of the aircraft are presented.
\end{abstract}

\section{Introduction}

$\mathrm{H}$ IGH-ALTITUDE Long-Endurance (HALE) vehicles are being developed for multiple applications, including environmental sensing, telecom relay, and military reconnaissance. These HALE concepts feature light wings with a high aspect ratio. These long and slender wings, by their inherent nature, can maximize lift to drag ratio. On the other hand, these wings may undergo large deformations during normal operating loads, exhibiting geometrically nonlinear behavior. Patil, Hodges, and Cesnik ${ }^{1}$ studied the aeroelasticity and flight dynamics of HALE aircraft. The results indicate the aeroelastic behavior and flight dynamics characteristic of the aircraft can be significantly changed due to the large deflection of the flexible wings. Van Schoor, Zerweckh and von Flotow ${ }^{2}$ studied aeroelastic characteristics and control of highly flexible aircraft. They used linearized modes including rigidbody modes to predict the stability of the aircraft under different flight conditions. Their results indicate that unsteady aerodynamics and flexibility of the aircraft should be considered so as to correctly model the dynamic system. This leads to the conclusion that the coupled effects between these large deflection and vehicle flexibility and flight dynamics (e.g., roll controllability) as well as other aeroelastic effects (e.g., gust response, flutter instability) must be properly accounted for in a nonlinear aeroelastic formulation. Drela ${ }^{3}$ modeled a complete flexible aircraft as an assemblage of joined nonlinear beams. In his work, the aerodynamic model was a compressible vortex/source-lattice with wind-aligned trailing vorticity. The nonlinear equation was solved by using a full Newton method. Through simplifications of the model, the computational size was reduced for iterative preliminary design.

In the last several years, the Air Force has been working on a new generation Intelligence, Surveillance, and Reconnaissance (ISR) platform, which is called "Sensorcraft." These are large HALE aircraft, with wing span of approximately $60 \mathrm{~m}$. At this moment, three basic platform shapes are being considered: wing-body-tail, single-wing and joined-wing configurations ${ }^{4}$.

\footnotetext{
*Associate Professor (cesnik@umich.edu), Department of Aerospace Engineering, Associate Fellow, AIAA.

${ }^{\dagger}$ Graduate Research Assistant (suw@umich.edu), Department of Aerospace Engineering.

Copyright $\bigcirc 2005$ by Carlos E. S. Cesnik and Weihua Su. Published by the American Institute of Aeronautics and Astronautics, Inc., with permission. 
Among the Sensorcraft concepts, the joined-wing configuration is the most unusual one. It was first proposed by Wolkovitch $^{5}$, who suggested that this new design would lead to possible weight savings and some aeroelastic benefits. However, the effects of structural deformation on the aerodynamic and aeroelastic responses are difficult to intuit and predict.

Livne $^{6}$ presented a comprehensive survey on the design challenges of joined-wing aircraft configurations. Therein, he presented a review of past works in joined-wing aeroelasticity and gave a qualitative discussion of their behavior in a multidisciplinary context. Much of the discussion in the paper dealt with structural and aeroelastic issues relating to the aft wing/tail. The in-plane loads due to structure deformation and changes in geometric stiffness give rise to non-intuitive aeroelastic behavior. Bending and twisting couplings of the entire structure cause natural frequencies and mode shapes to shift. The tendency for buckling and divergence in the aft member is of major concern when trying to reduce weight. The finding of rear wing divergence to be more critical than flutter is counterintuitive, since the aft wing is supported at the joint. This phenomenon seems associated with a reduction in structural stiffness due to the in-plane compressive loads in the rear members. The geometry of the joint between forward and aft wings is also of importance because it plays a major role in how in-plane, bending, and torsion loads are transferred. For instance, a pinned joint may allow upward buckling of the aft wing, while a fixed rigid joint may allow the aft wing to buckle downward, since bending moments are transferred across the joint. Lin, Jhou and Stearman ${ }^{7}$ studied the influence of joint fixity on the aeroelastic characteristics of the joined-wing. They suggested that the fixed joint provide the best characteristic.

Weight estimation of joined-wing has been studied before. The structural weight of a joined-wing and that of a Boeing 727 were compared by Samuels ${ }^{8}$. His conclusion is the joined-wing's structural weight is $12-22 \%$ lighter than that of a conventional configuration, while in Ref. 9, Gallman and Kroo concluded that the structural weight was increased by $13 \%$ when including the buckling constraint of the aft wing. Therefore, joined-wing configurations are not guaranteed to be lighter than conventional ones. Miural, Shyu, and Wolkovitch ${ }^{10}$ found that the structural weight of a joined-wing strongly depend on geometry and structural arrangement of the wing. Blair and Canfield ${ }^{11}$ described an integrated design process for generating high fidelity analytical weight estimations of joined-wing configurations. They suggested an integrated design process that can bring together different software package, such as NASTRAN, PanAir, and integrate them through the Air Vehicles Technology Integration Environment (AVTIE), so that structures, aerodynamics and aeroelastic analysis are incorporated.

Structural optimization for joined-wing was done by Kroo, Gallman and Smith ${ }^{9,12,13}$. The wings were modeled as boxed-beams to study for the effects of several parameters on the trimmed performance of joined-wing aircraft. In Ref. 12, the results show that the wings with similar aspect ratio joining at $60-75 \%$ of the front wing span are optimal for the given condition. Asymmetric material distribution leads to more drag reduction than symmetric distribution. They also suggest using fully stressed design method since it is computationally cheaper even though it produced a result that is a little bit heavier and with more direct operation cost (DOC). Roberts, Canfield and Blair ${ }^{14}$ performed the structural optimization for a joined-wing Sensorcraft. They identified some critical points in a flight index and optimized the Sensorcraft with respect to these critical points. Their results suggest the necessity of nonlinear structural analysis. More recently, Rasmussen, Canfield and Blair ${ }^{15}$ performed an optimum design for joined-wing aircraft that utilizes both structural and aerodynamic analysis. Response surface method was employed within their scheme of design optimization.

Different technologies, in addition to the traditional ailerons, have been included in structural design of joinedwing Sensorcraft, in order to improve their performance. Active aeroelastic wing (AAW) ${ }^{16}$ technology was applied in a joined-wing Sensorcraft for his purpose of minimum deformations of the antenna embedded in the wing skins, in addition to generate maneuver loads for the Sensorcraft.

Meanwhile, Cesnik and Brown ${ }^{17}$ studied some of aeroelastic characteristics of the joined-wing aircraft with the concept of active warping actuation for maneuver load generation. The active piezoelectric concepts have their advantage over traditional ailerons in terms of structural integration. However, according to the studies of Ref. 17, the wing-warping design based on current anisotropic piezoelectric actuators (APA) technology presents a terminal roll rate which is three times smaller than the aileron concept due to limited actuator authority.

From the elicitation of previous researches, deformation of the structure of joined-wing Sensorcraft at a certain location may produce large changes in angle of attack in the lifting surfaces at other locations, due to their complex structure. Efforts to minimize structural weight may create aeroelastic instabilities that are not encountered in conventional aircraft design. For joined-wing aircraft, the first sign of failure may be associated with the buckling of the aft members as the structure is softened. Flutter and divergence may also become a problem in these members due to the reduction in structural frequency as they go into compression. As the aircraft becomes more flexible, the nature of the geometric structural nonlinearities become more important and the lift distribution on the aircraft may be adversely affected. 
Not being limited within the scope of joined-wing configurations, the large overall vehicle size associated with the different Sensorcraft configurations being studied may lead to a very flexible aircraft overall. In fact, long and slender fuselage and tail surfaces result in elastic coupling with the lifting surfaces. This directly impacts the trimming of the vehicle, and the couplings among roll, yaw, and pitch require the use of nonlinear aeroelastic and flight dynamics analyses to predict vehicle response, design of control laws, and its overall guidance. These flexibility effects may make the response of the vehicle very different than its rigid or linearized models. The current study is an extension of the work of Ref. 18, allowing all members of the vehicle to be flexible. There are limitless aspects of fully flexible aircraft that are necessary to be studied, however, this paper focuses on two key points:

1) New approach for the modeling of the complex nonlinear structural system of fully flexible aircraft;

2) Assessment of the effects of induced flexibility of fuselage and tail on roll performances and stabilities of fully flexible Sensorcraft, particularly applied to a single-wing and joined-wing configurations.

\section{Theoretical Formulation}

In the proposed formulation, the vehicle is allowed six rigid-body and multiple flexible degrees of freedom. The structures are allowed fully coupled three-dimensional bending, twisting, and extensional deformations. Control surfaces may be included for maneuver studies. Inclusion of flexible fuselage and vertical tail are new to the formulation. A finite-state unsteady airloads model is integrated into the system equations, with the exception of the fuselage (at this stage). The model allows for a low-order set of nonlinear equations that can be put into state-space form to facilitate control design.

\section{A. Element Description}

Consider a typical slender structural component (e.g. wing) being represented as shown in Fig. 1. In the work of Ref. 17, specialized beam elements were developed that have four local strain degrees-of-freedom: extension, twist, and two bending ones. Fig. 2 exemplifies the deformations of constant-strain elements.

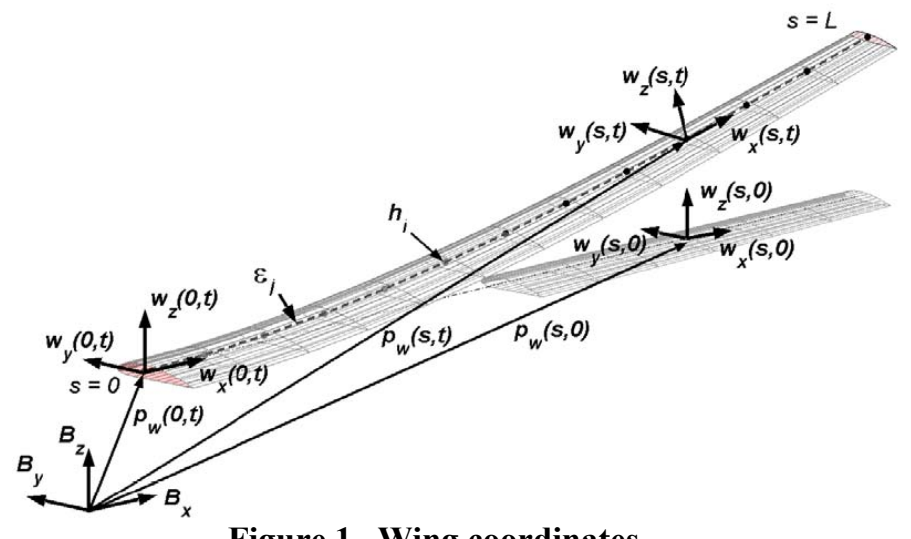

Figure 1. Wing coordinates

Each node along the beam is determined by a vector consisting of 12 components. Suppose the beam reference frame is $w$, which is a function of the natural beam coordinate $s$, the 12-component vector is denoted as,

$$
h(s)^{T}=\left[p_{w}(s)^{T}, w_{x}(s)^{T}, w_{y}(s)^{T}, w_{z}(s)^{T}\right]
$$

where, $p_{w}$ is the position of frame $w$ in the body coordinate, $w_{x}, w_{y}$, and $w_{z}$ are the direction vectors pointing along the beam axis, toward the leading edge, and normal to the airfoil, respectively (see Fig. 1). As discussed in Ref. 17 , the governing equation, which relates the dependent displacements to the independent strains, is,

$$
\frac{\partial h(s)}{\partial s}=A(s) h(s)
$$

where, $A$ is a matrix function of the strains. 


$$
A(s)=\left[\begin{array}{c|c:c:c}
0 & 1+\varepsilon_{x}(s) & 0 & 0 \\
\hline 0 & 0 & \kappa_{z}(s) & -\kappa_{y}(s) \\
\hdashline 0 & -\kappa_{z}(s) & 0 & \kappa_{x}(s) \\
\hdashline 0 & \kappa_{y}(s) & -\kappa_{x}(s) & 0
\end{array}\right]
$$

where the blocks are all $3 \times 3$ diagonal matrices. The solution of Eq. (2) can be given by Eq. (4), with the assumption that the element has a constant strain vector

$$
h(s)=e^{A s} h_{0}=e^{G(s)} h_{0}
$$

where, $h_{0}$ is the beam boundary conditions.

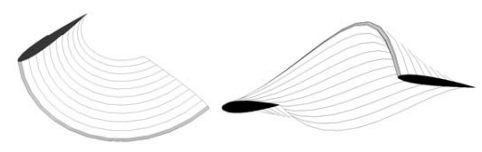

Figure 2. Deformations of a typical constant-strain element.

The total virtual work done on an element due to all internal and external forces and moments can be written as,

$$
\delta W=-\delta h^{T} M \ddot{h}-\delta \varepsilon^{T} K \varepsilon+\delta \varepsilon^{T} B_{v} v-\delta h^{T} N g+\delta p^{T} B_{F} F^{d s t}+\delta \theta^{T} B_{M} M^{d s t}+\delta p^{T} F^{p t}+\delta \theta^{T} M^{p t}
$$

where the terms involved include the effects of inertia $(M \ddot{h})$, gravity field $(N g)$, internal strain $(\varepsilon)$, piezoelectric actuation $(v)$, distributed forces $\left(F^{d s t}\right)$ and moments $\left(M^{d s t}\right)$, and point forces $\left(F^{p t}\right)$ and moments $\left(M^{p t}\right)$.

\section{B. Member and Inter-Member Equations}

In the model of fully flexible aircraft, the fuselage and the vertical tail are both modeled as slender beams, similarly to the wings. Therefore, it is necessary to model a split beam system as illustrated in Fig. 3. For simplicity, consider three members in this beam system. Member 1 consists of two elements and Members 2 and 3 each consist of one element only. Every element has three nodes, each with the degrees of freedom given by Eq. (1). The proposed approach here is to modify the original kinematics of Ref. 17 to allow the analysis of split beams.

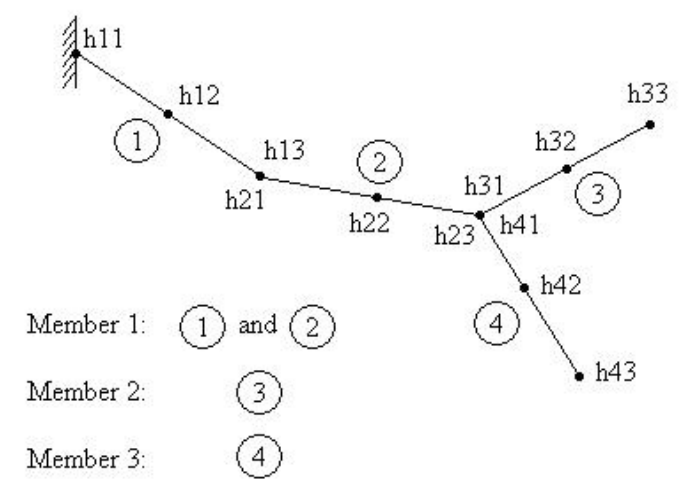

Figure 3. A split (or bifurcated) beam system.

The kinematics for these members is obtained by marching the element kinematics from the boundary node to the end nodes at each branch, which can be written as follows: 


\begin{tabular}{|c|c|c|c|c|c|}
\hline \multicolumn{3}{|c|}{ Element 1} & \multicolumn{3}{|c|}{ Element 2} \\
\hline Node 1 & Node 2 & Node 3 & Node 1 & Node 2 & Node 3 \\
\hline$h_{11}=h_{0}$ & $h_{12}=e^{G_{1}} h_{11}$ & $h_{13}=e^{G_{1}} h_{12}$ & $h_{21}=D_{21} h_{13}$ & $h_{22}=e^{G_{2}} h_{21}$ & $h_{23}=e^{G_{2}} h_{22}$ \\
\hline \multicolumn{3}{|c|}{ Element 3} & \multicolumn{3}{|c|}{ Element 4} \\
\hline Node 1 & Node 2 & Node 3 & Node 1 & Node 2 & Node 3 \\
\hline$h_{31}=D_{32} h_{23}$ & $h_{32}=e^{G_{3}} h_{31}$ & $h_{33}=e^{G_{3}} h_{32}$ & $h_{41}=D_{42} h_{23}$ & $h_{42}=e^{G_{4}} h_{41}$ & $h_{43}=e^{G_{4}} h_{42}$ \\
\hline
\end{tabular}

where $h_{i j}$ is the displacement of the $j$ th node of the $i$ th element. $D_{i j}$ contains the direction cosines, accounting for the different directions of different elements at the connection. These equations can be written into a matrix form as

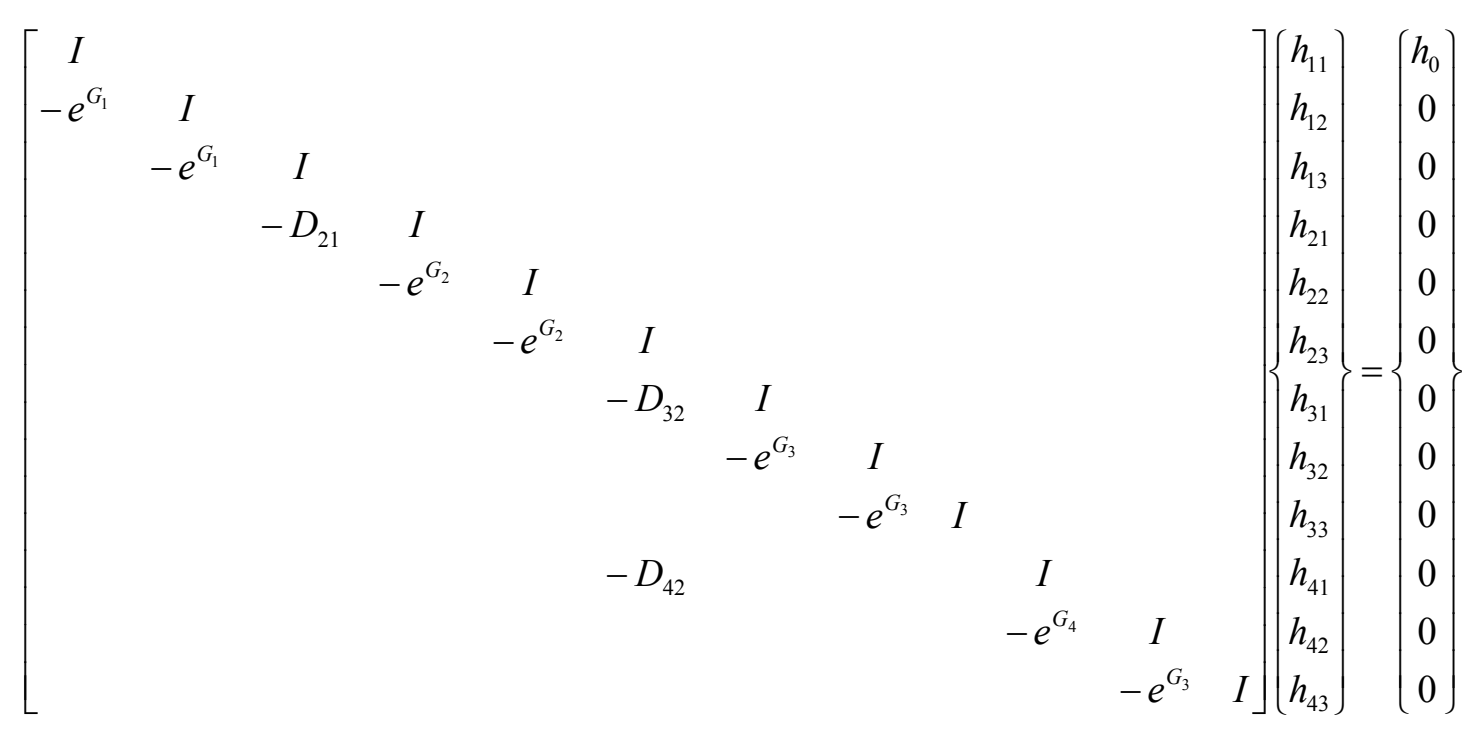

Note that the location of $D_{42}$ reflects the relation between members 2 and 4.

The other parts of the current framework, such as the construction of stiffness matrix, mass matrix, equation of motion, and the solution procedure are basically left unchanged, except for some modifications to make them compatible with the new kinematics relation added into the existing framework. This framework is now enhanced with the ability to model the highly flexible aircraft with flexible fuselage and vertical tail. Fig. 4 shows a built-up model.

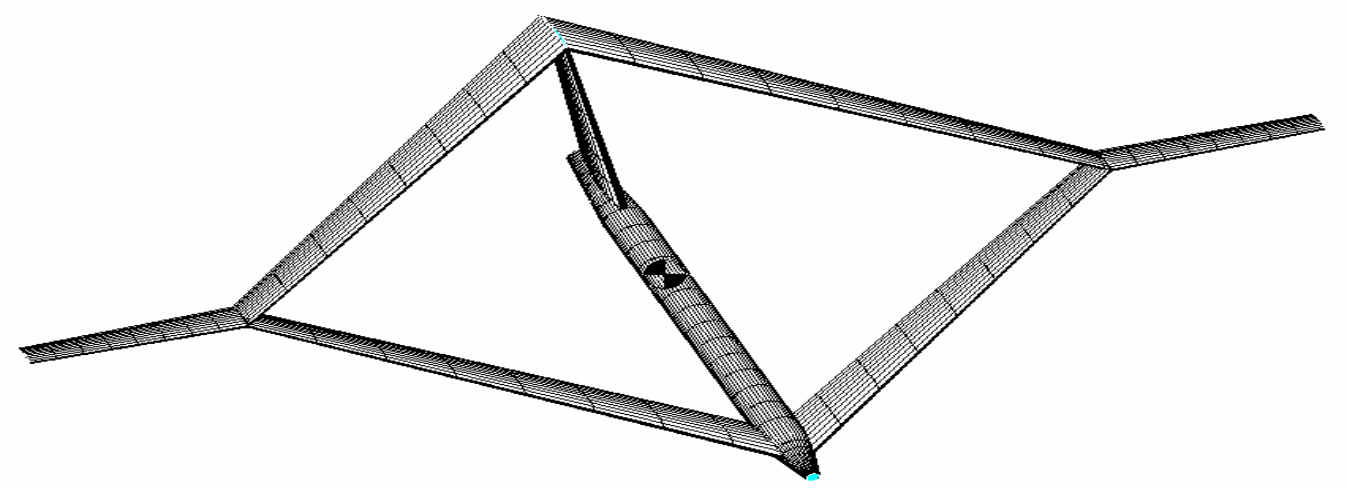

Figure 4. Illustration of a built-up joined wing aircraft with flexible fuselage and vertical tail. 


\section{Equations of Motion}

The equations of motion of the system are obtained by following the Principle of Virtual Work. With the six rigid-body degrees of freedom, the system structural degrees of freedom are represented by the column matrix $q$, where

$$
\dot{q}=\left[\dot{\varepsilon}_{1}^{T}, \dot{\varepsilon}_{2}^{T}, \ldots, \dot{\varepsilon}_{n}^{T}, V_{B}^{T}, \omega_{B}^{T}\right]^{T}
$$

and $\varepsilon_{i}$ contains the strain variables for wing member $i, V_{B}$ and $\omega_{B}$ are the linear velocity and angular velocity of the vehicle reference point (original of the $\mathrm{B}$ frame), respectively, represented in the body frame, $B$. The dependent variables for the entire vehicle are collected into the column matrix $H$,

$$
\dot{H}=\left[\dot{h}_{1}^{T}, \dot{h}_{2}^{T}, \ldots, \dot{h}_{n}^{T}, V_{B}^{T}, \omega_{B}^{T}\right]^{T}
$$

The dependent degrees of freedom are related to the independent degrees of freedom through a Jacobian matrix relation

$$
H=f(q), \quad d H=\left[\frac{\partial H}{\partial q}\right] d q=\left[J_{H q}(q)\right] d q
$$

The expression for virtual work on the vehicle is now given by

$$
\delta W=\delta q^{T}\left(-\bar{M} \ddot{q}-\bar{C} \dot{q}-\bar{K} q+\bar{N} g+\bar{B}_{v} V+\bar{B}_{F 1} F^{d s t}+\bar{B}_{F 2} F^{p t}+\bar{B}_{M 1} M^{d s t}+\bar{B}_{M 2} M^{p t}+B_{q 0} q_{0}+B_{H} H\right)
$$

where $\bar{M}, \bar{C}$, and $\bar{K}$ are generalized mass, damping, and stiffness matrices corresponding to the independent degrees of freedom of the total system. Note that the matrices above are all assembled ones with respect to global degrees of freedom. The principle of virtual work requires that the total virtual work done on the system be equal to zero, leading to the equations of motion,

$$
\bar{M} \ddot{q}+\bar{C} \dot{q}+\bar{K} q=B_{V} V+B_{F 1} F^{d s t}+B_{F 2} F^{p t}+B_{M 1} M^{d s t}+B_{M 2} M^{p t}+\bar{N} g+B_{q 0} q_{0}+B_{H} H
$$

The distributed loads, $F^{d s t}$ and $M^{d s t}$, are divided into aerodynamic loads and user supplied loads. The aerodynamic loads evaluated at the current state have the incremental form

$$
\begin{aligned}
& F^{\text {aero }}(t)=F^{\text {aero }}\left(t_{0}+\Delta t\right) \approx F_{0}\left(q_{0}, \dot{q}_{0}, \lambda_{0}\right)+F_{\ddot{q}} \ddot{q}+F_{\dot{q}} \Delta \dot{q}+F_{q} \Delta q+F_{\lambda} \Delta \lambda \\
& M^{\text {aero }}(t)=M^{\text {aero }}\left(t_{0}+\Delta t\right) \approx M_{0}\left(q_{0}, \dot{q}_{0}, \lambda_{0}\right)+M_{\ddot{q}} \ddot{q}+M_{\dot{q}} \Delta \dot{q}+M_{q} \Delta q+M_{\lambda} \Delta \lambda
\end{aligned}
$$

here $\lambda$ is column matrix of induced flow states as described in Ref. 19. The induced flow states are governed by a differential equation of the form

$$
\dot{\lambda}=L_{1} \lambda+L_{2} \ddot{q}+L_{3} \dot{q}
$$

The aeroelastic equations of motion are obtained by moving the state dependent aerodynamic loads over to the left hand side of Eq. (11) and augmenting the structure states with the induced flow states, which can be represented in state space form as

$$
\dot{x}=A(x) x+B(x) u(x, t)
$$

where the state vector is now given by

$$
x=\left[q^{T}, \dot{q}^{T}, \lambda^{T}\right]^{T}
$$




\section{Numerical Studies}

To exemplify the capability of the new formulation and study the impact of overall vehicle flexibility, two different baseline vehicles were created. They represent two different configurations: a single-wing and a joinedwing configuration. Seven flight index points represent the nominal mission profile, as indicated in Fig. 5. At each index point, the altitude, fuel mass, and nominal flight velocity are specified. The index points represent: (1) takeoff, (2) climb, (3) cruise ingress, (4) cruise/loiter/cruise, (5) cruise egress, (6) decent, and (7) landing. The fuel burn determines the duration of each flight segment. The nominal flight speed at each index point is based on the cruise speed (input parameter), and is computed such that the dynamic pressure is constant (constant indicated air speed). At each flight index point, the vehicle is trimmed for equilibrium in horizontal flight at given flight speed.
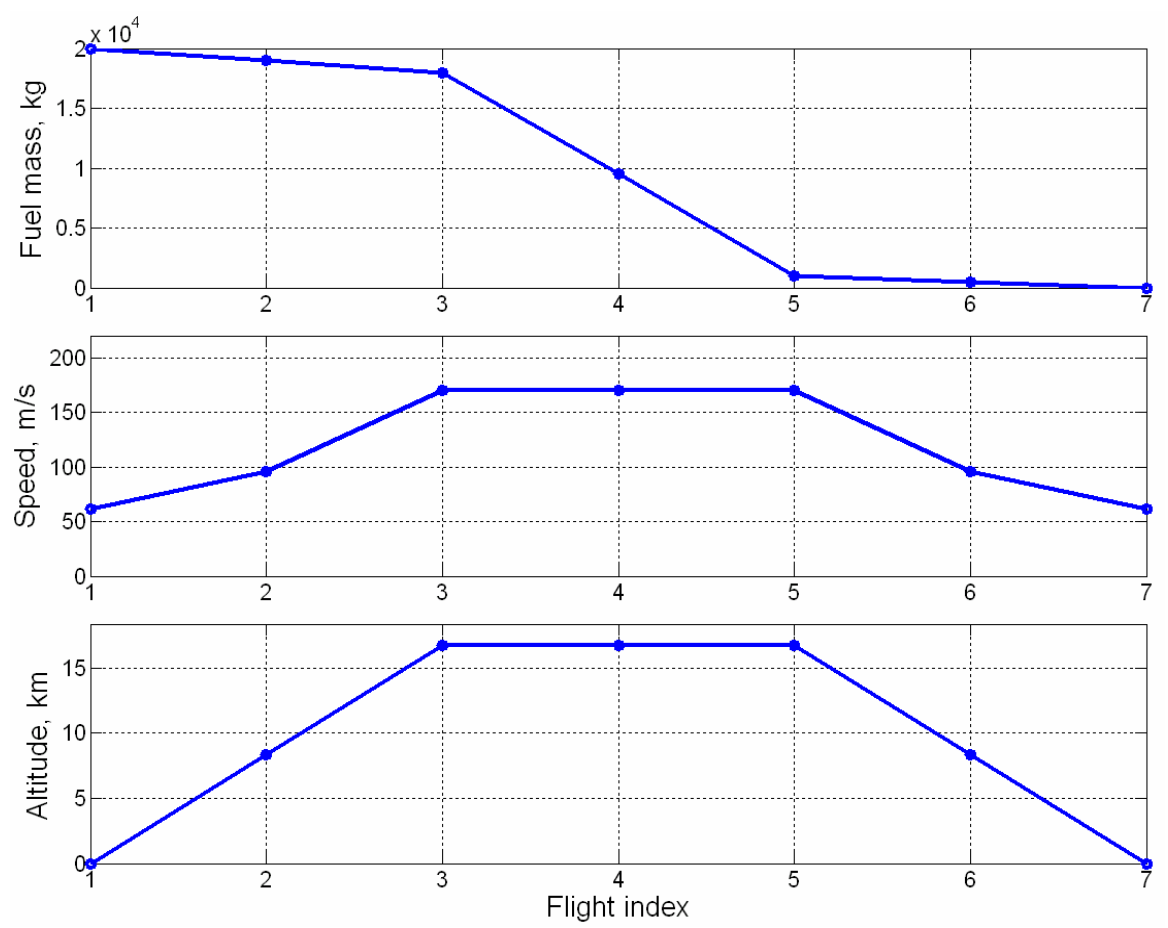

Figure 5. Basic mission profile.

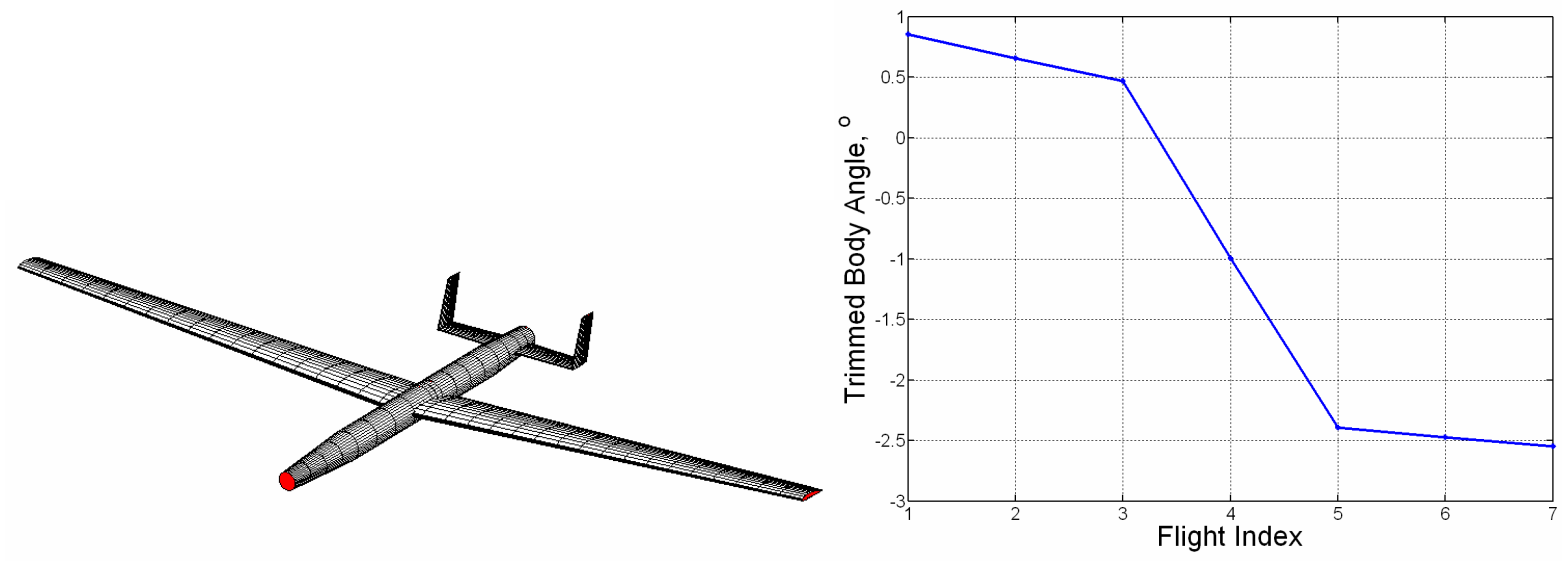

Figure 6. Baseline single-wing vehicle and trimmed body angle of attack. 


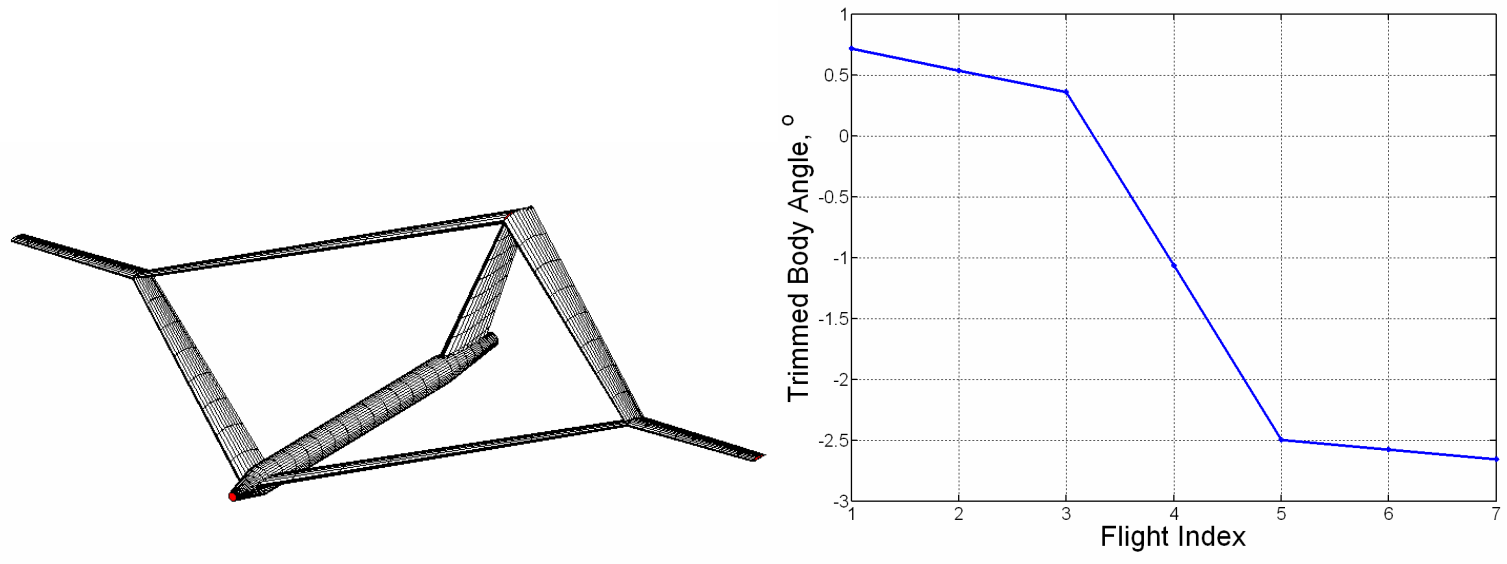

Figure 7. Baseline joined-wing vehicle with unswept outer wings (where ailerons are present).

\section{A. Baseline Vehicles}

Three sets of constraints were defined to help sizing the baseline designs: strength (based on first-ply failure) at $1.5 \mathrm{-g}$ load, strength based on gust loads, and minimum linearized flutter margin. For both vehicles, the $1.5 \mathrm{-g}$ load factor was shown to be the critical constraint and the wing structural thickness distribution was sized for fullystrained design along span. A description of the design process can be found in Ref. 17.

\section{Single-wing Configuration}

Geometry. From top view, the vehicle shape is symmetric. As indicated in Fig. 8, the wings are divided into nine regions, and the horizontal and vertical tail surfaces are both divided into two regions for definition of crosssectional property distribution. For simplicity, NACA 4415 is chosen as the airfoil and it is kept constant throughout the wing members. The wing contains three independent ailerons, which present in regions 3 and 4, 5 to 7 , and 8 and 9, as indicated in Fig. 8. These ailerons occupy $20 \%$ of the chord from $22 \%$ span to the tip of the wing, which are allowed to deflect $+/-30^{\circ}$.

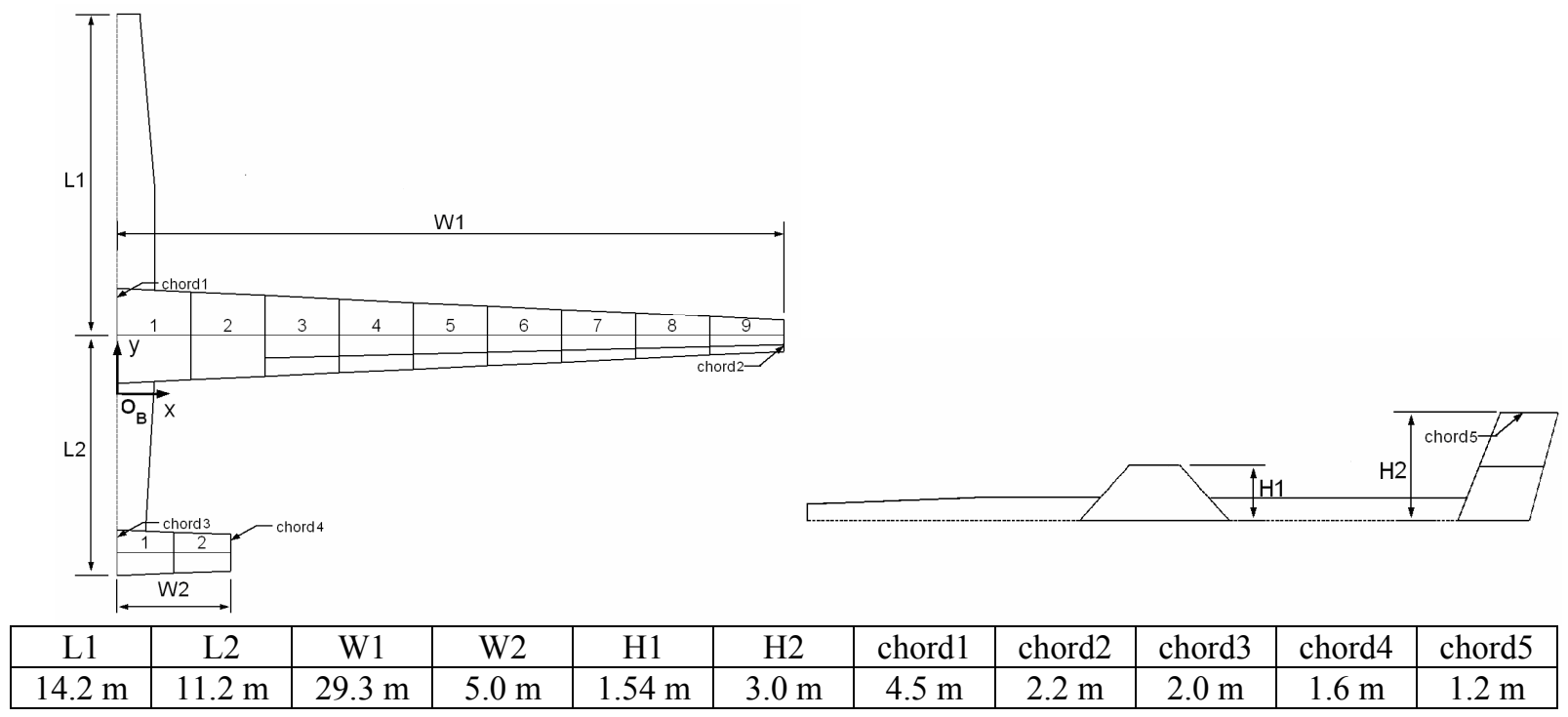

Figure 8. Baseline single-wing configuration sensorcraft vehicle geometry.

Vehicle Mass Breakdown. The vehicle mass breakdown is given in Table 1. The fuel is assumed to be distributed up to half span of the wings, independent of the total amount of fuel on board. The fuselage contains no fuel. 
Table 1. Vehicle mass distribution for single-wing configuration.

\begin{tabular}{|l|l|}
\hline Fuselage structure + payload + engine mass & $4,000 \mathrm{~kg}$ \\
\hline Fuel mass & $20,000 \mathrm{~kg}$ \\
\hline Tails structure mass & $420 \mathrm{~kg}$ \\
\hline Vehicle total wing structure mass & $4,230 \mathrm{~kg}$ \\
\hline Vehicle gross take-off mass & $28,650 \mathrm{~kg}$ \\
\hline
\end{tabular}

Cross-sectional Inertia and Stiffness Distributions. The stiffness and inertia properties of each cross-section of the wing, tail and fuselage can be found in the Appendix (Figs. A1 to A21). Note that nonstructural masses of 155 $\mathrm{kg}$ each is used for the modeling of aircraft payload, which are assigned at each node of the fuselage for simplicity.

\section{Joined-wing Configuration}

Geometry. From top view, the vehicle shape is symmetric (although one may want to vary the forward/aft location of the joint). The wings are denoted right front wing (with inner and outer wings), left front wing, right aft wing (with inner-wing only), and left aft wing. Right and left are determined as in Fig. 9 (as viewed from top with nose pointing up). The front wings are divided into eight regions while the aft wings are divided into four regions for definition of cross-sectional properties distribution. The members of all inner wings are identical in construction, and the material distribution follows the numbering convention indicated in Fig. 9. For simplicity, NACA 4415 is chosen as the airfoil and it is kept constant throughout the wing members. The outer wing contains a $50 \%$ $\operatorname{span} / 20 \%$-chord aileron that is allowed $30^{\circ}$ of amplitude deflection.
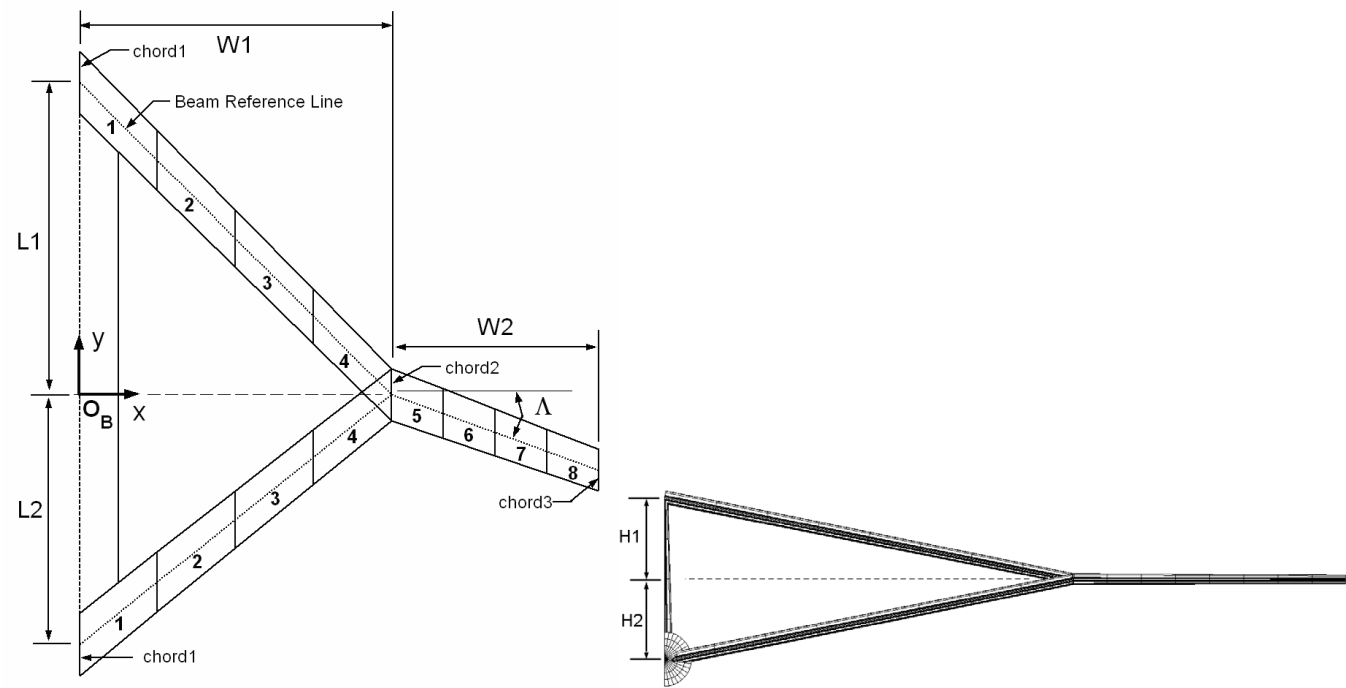

\begin{tabular}{|c|c|c|c|c|c|c|c|c|c|}
\hline L1 & L2 & W1 & W2 & H1 & H2 & chord1 & chord2 & chord3 & $\Lambda$ \\
\hline $15 \mathrm{~m}$ & $15 \mathrm{~m}$ & $20 \mathrm{~m}$ & $10 \mathrm{~m}$ & $4 \mathrm{~m}$ & $4 \mathrm{~m}$ & $3.5 \mathrm{~m}$ & $2 \mathrm{~m}$ & $1.5 \mathrm{~m}$ & 0 \\
\hline
\end{tabular}

Figure 9. Baseline joined-wing sensorcraft vehicle geometry.

Vehicle Mass Breakdown. The vehicle mass breakdown is given in Table 2. The fuel is assumed to be distributed evenly throughout the inner and outer wings, independent of the total amount of fuel on board. The fuselage contains no fuel.

Table 2. Vehicle mass distribution for joined-wing configuration.

\begin{tabular}{|l|l|}
\hline Fuselage structure + payload + engine mass & $4,000 \mathrm{~kg}$ \\
\hline Fuel mass & $20,000 \mathrm{~kg}$ \\
\hline Vertical tail structure mass & $550 \mathrm{~kg}$ \\
\hline Vehicle total wing structure mass & $3,440 \mathrm{~kg}$ \\
\hline Vehicle gross take-off mass & $27,990 \mathrm{~kg}$ \\
\hline
\end{tabular}


Cross-sectional Inertia and Stiffness Distributions. The stiffness and inertia properties of the wing, vertical tail and fuselage can be found in the Appendix (Figs. A22 to A42). Note that nonstructural masses of $100 \mathrm{~kg}$ each is used for the modeling of aircraft payloads, which are attached at each node of the fuselage for simplicity.

\section{B. Models for Different Degrees of Flexibility}

To assess the effects of the flexibility of different parts of the vehicles on their roll response and stability, five different models are considered for both single-wing and joined-wing configurations. They are summarized in Tables 3 and 4 .

Table 3. Different levels of flexibility to be considered for single-wing configuration.

\begin{tabular}{|c|c|c|c|}
\hline & Fuselage & Tails & Wings \\
\hline Model 1 & Rigid & Rigid & Flexible \\
\hline Model 2 & Rigid & Flexible & Flexible \\
\hline Model 3 & Rigid & 4 Flexible & Flexible \\
\hline Model 4 & Flexible & Rigid & Flexible \\
\hline Model 5 & Flexible & Flexible & Flexible \\
\hline
\end{tabular}

Table 4. Different levels of flexibility to be considered for joined-wing configuration.

\begin{tabular}{|c|c|c|c|c|}
\hline & Fuselage & Vertical Tail & Inner Wings & Outer Wings \\
\hline Model 1 & Rigid & Rigid & Rigid & Flexible \\
\hline Model 2 & Rigid & Rigid & Flexible & Flexible \\
\hline Model 3 & Rigid & Flexible & Flexible & Flexible \\
\hline Model 4 & Flexible & Rigid & Flexible & Flexible \\
\hline Model 5 & Flexible & Flexible & Flexible & Flexible \\
\hline
\end{tabular}

In the above tables, the "rigid" members are modeled with 100 times the nominal stiffnees, representing almost rigid cases, whereas the " $4 *$ Flexible" members are modeled to have $25 \%$ of the nominal stiffness, representing an extra flexible case.

\section{Roll Responses}

In the study of roll response, the analysis takes place at flight index 5 (see Fig. 5), where the flight condition is $16.7 \mathrm{~km}$ altitude, and $170 \mathrm{~m} / \mathrm{s}$. The trimmed body angle of attack is $-2.40^{\circ}$ for single-wing and $-2.50^{\circ}$ for joinedwing configuration, respectively. These angles, however, may vary for the models with different level of flexibility. To achieve the roll motion, anti-symmetric aileron deflection is employed. As a comparison, both linearized and non-linear approaches are implemented ${ }^{17}$ here. In the linearized approach, the aircraft is first brought to its nonlinear steady state with roll motion locked. Both the roll moment and roll damping are calculated based on this deformed structure. The roll responses are then calculated based on these quantities. This approach has the advantage of being computationally efficient, which is very desirable for preliminary studies. On the other hand in the non-linear approach, the deformed shape of the aircraft is updated at each time step, and all the aerodynamic loads are calculated according to the updated deformed shapes. Although more time consuming, this presents the most accurate representation of the maneuver.

Figs. 10 and 11 show the comparison of the roll results from linearized and nonlinear approach for the fully flexible model (model 5) of the single-wing configuration. From the plots, one can see that there is over- $15 \%$ difference in the steady state roll rate. This reflect at the different roll angle values at given instant of time. However, this may not be an issue for shallow angle roll maneuvers, where the difference between the two models is very small. 


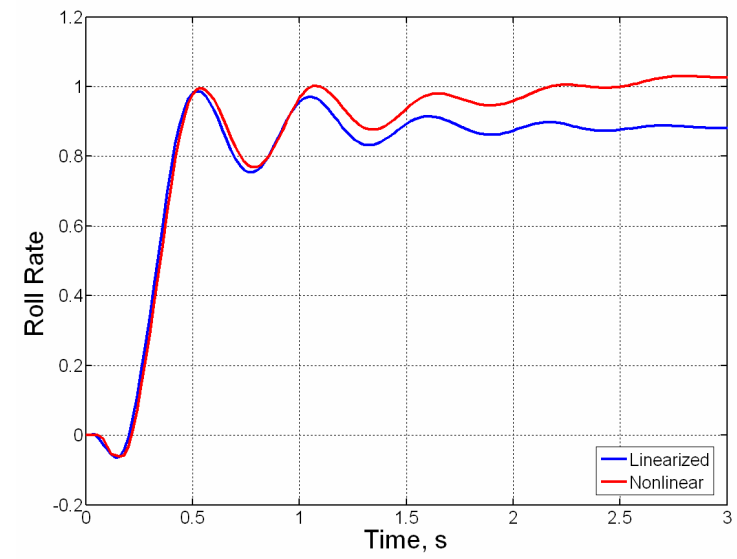

Figure 10. Comparison of roll rate results from linearized and nonlinear approaches (Normalized wrt $\left.42.59^{\circ} / \mathrm{s}\right)$.

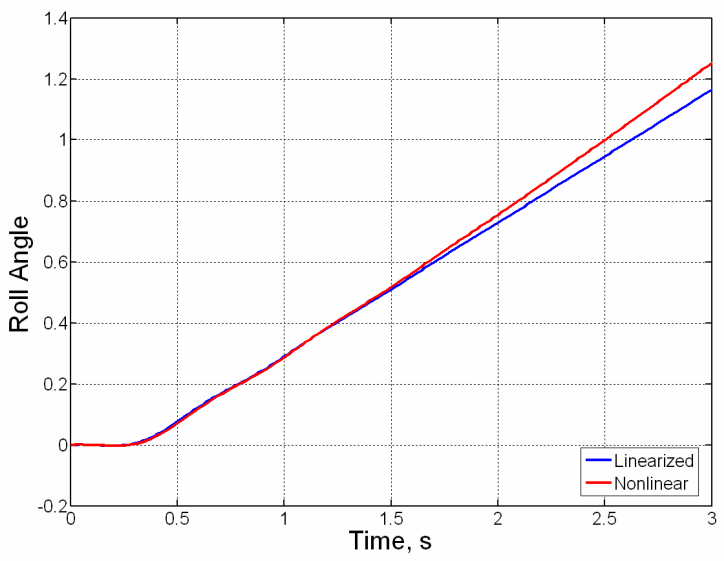

Figure 11. Comparison of roll angle results from linearized and nonlinear approaches (Normalized wrt 86.29 ${ }^{\circ}$ ).

Figs. 12 to 15 show the roll response of different models of the single-wing configuration. As it can be seen from the pictures, the flexibility of the fuselage and the tails does not play an important role in the roll response of this aircraft configuration.

Figs. 16 to 19 show the roll response of different models of the joined-wing configuration. For this configuration, there is a significant difference between the linearized and fully nonlinear approaches for roll analysis, particularly for the terminal roll rate. Moreover, as it can be seen from Figs. 16 and 18, the additional vehicle flexibility brings more complexity to the roll response as it starts developing. Also the maximum roll rate that the vehicle can reach is actually lower than what the semi-rigid model can predict (see Figs. 17 and 19). As it can also be seen from the figures, even though the flexibility of the fuselage brings oscillations to the roll rate responses, the overall roll angle does not show a significant reduction. On the other hand, the induced flexibility of the vertical tail brings both the oscillations of the roll response and reductions to the overall roll angle.

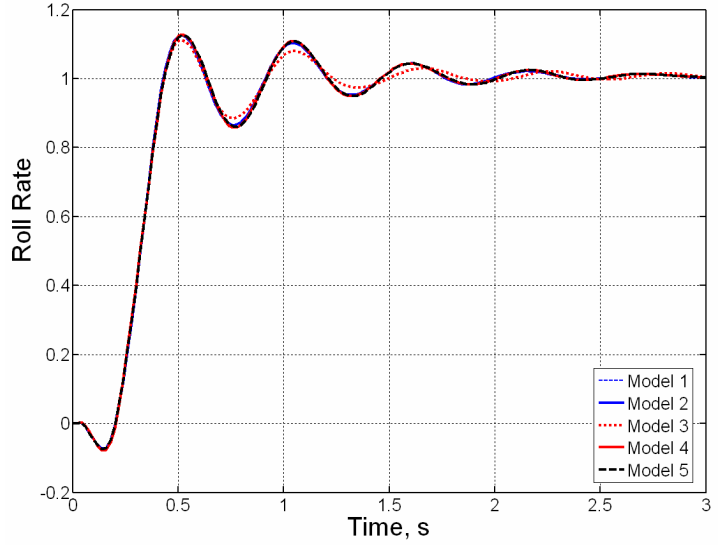

Figure 12. Linearized roll rate for single-wing configuration (Normalized wrt $37.32 \%$ s).

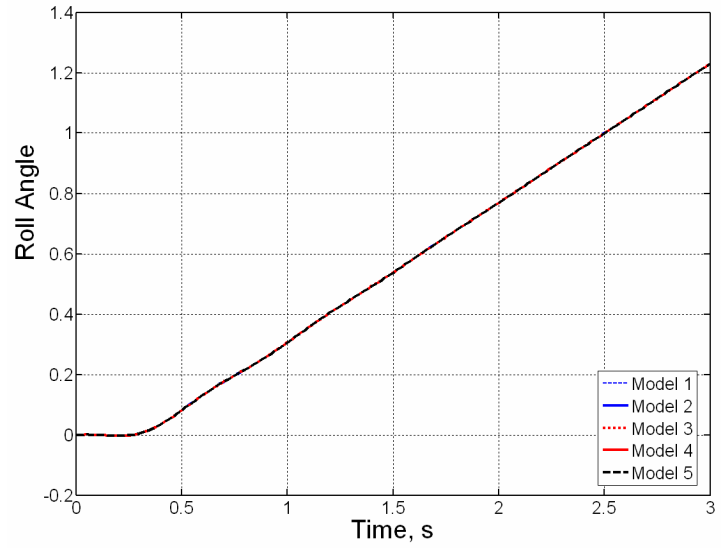

Figure 13. Linearized roll angle for single-wing configuration (Normalized wrt 81.67 ${ }^{\circ}$ ). 


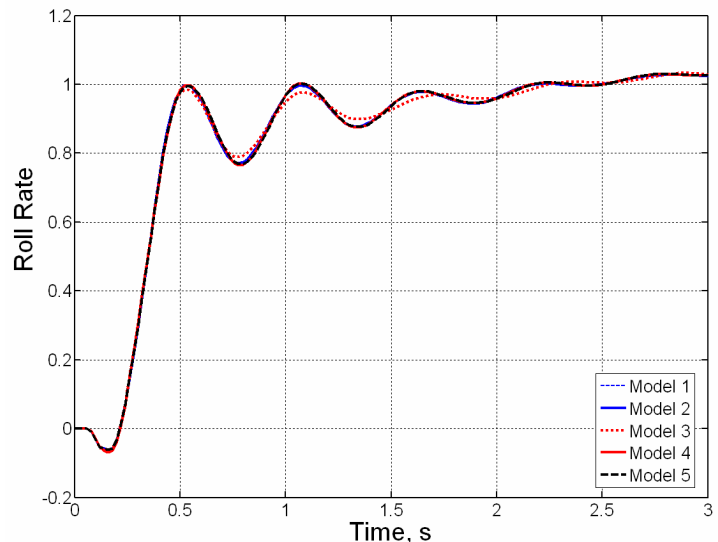

Figure 14. Nonlinear roll rate for single-wing configuration (Normalized wrt $42.59^{\circ} / \mathrm{s}$ ).

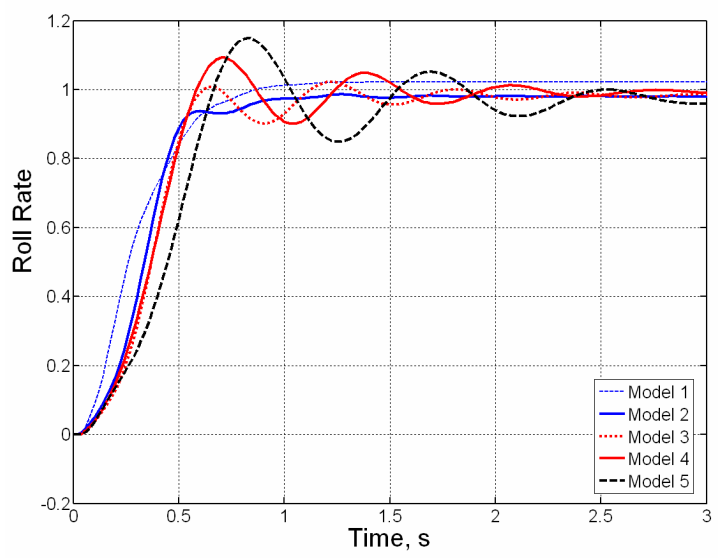

Figure 16. Linearized roll rate for joined-wing configuration (Normalized wrt $29.98^{\circ} / \mathrm{s}$ ).

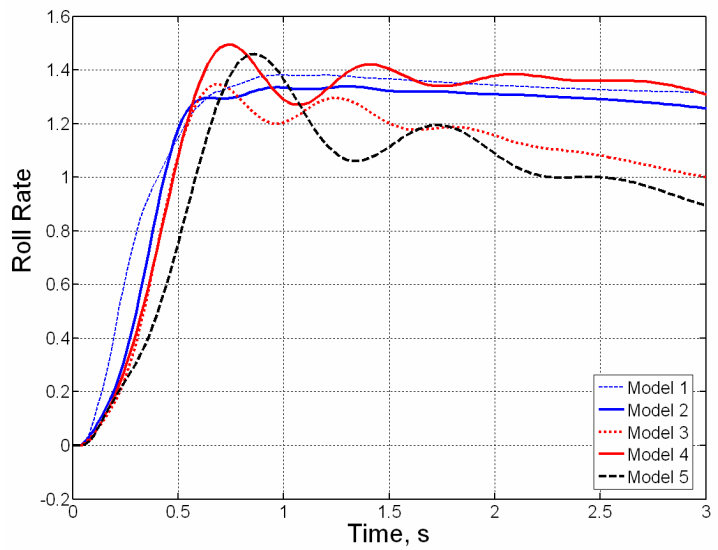

Figure 18. Nonlinear roll rate for joined-wing configuration (Normalized wrt $21.46^{\circ} / \mathrm{s}$ ).

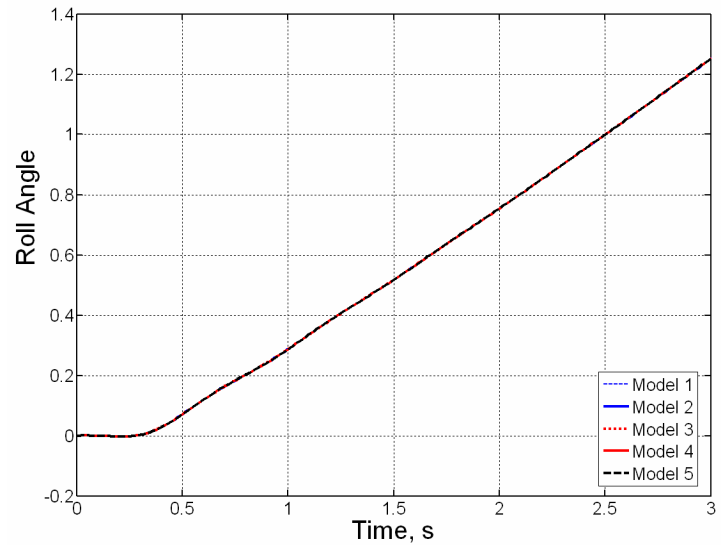

Figure 15. Nonlinear roll angle for single-wing configuration (Normalized wrt $86.29^{\circ}$ ).

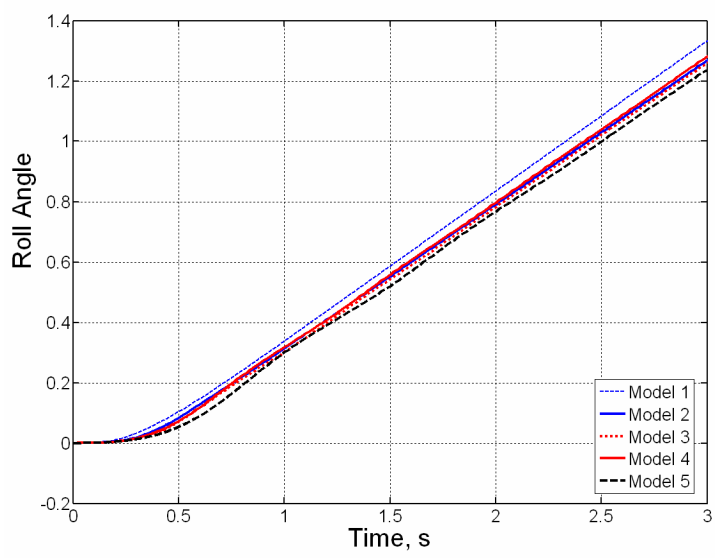

Figure 17. Linearized roll angle for joined-wing configuration (Normalized wrt $61.56^{\circ}$ ).

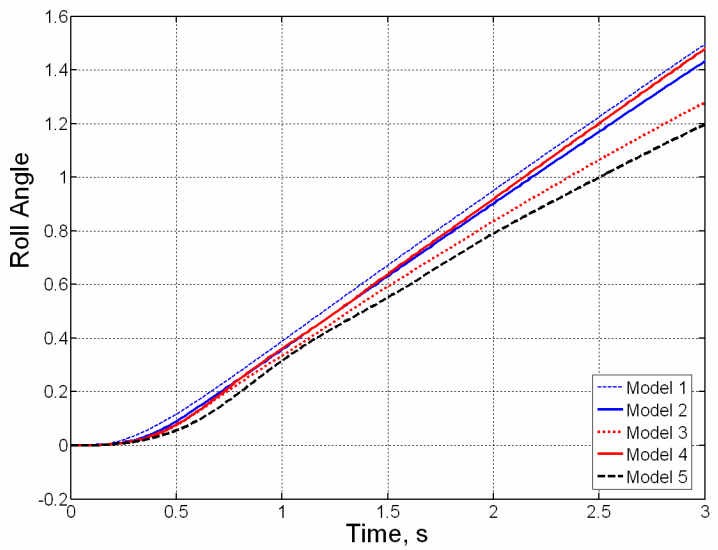

Figure 19. Nonlinear roll angle for joined-wing configuration (Normalized wrt $52.16^{\circ}$ ). 


\section{Dynamic Stability}

For both the single-wing and joined-wing configurations, the flutter speed is approximated at each flight index point by determining the stability characteristics of the linearized system about its nonlinear equilibrium condition. The calculated flutter speeds are plotted in Figs. 20 and 25 for single-wing and joined-wing configurations, respectively.

For the single-wing configuration, the induced flexibility of the fuselage reduces the flutter speed slightly. However, this effect is very small, almost negligible. The reduction of the flutter speed due to the induced flexibility of the tail should be considered carefully. In the studies, overall system stabilities are calculated and analyzed, which includes both the wings and the tails. Since the relative elastic coupling between the wing and tail is weak (i.e., relatively rigid fuselage), one would not expect any significant influence of the tail on the flutter characteristics of the wing. This explains why there is nearly no change in the flutter speed when the tail is set from rigid to flexible. However, if the stiffness of the tail is further reduced (say, $25 \%$ of the nominal stiffness), there will be a significant decrease of the tail flutter speed, which ended up lower than that of the wing. This is shown in shown in Fig. 20 (Model 3). This can also be observed from the flutter modes. Figs. 21 and 22 show the flutter modes of the Model 3, which has fluttering tail. But in Model 5, the flutter comes from the wings as indicated in Figs. 23 and 24.

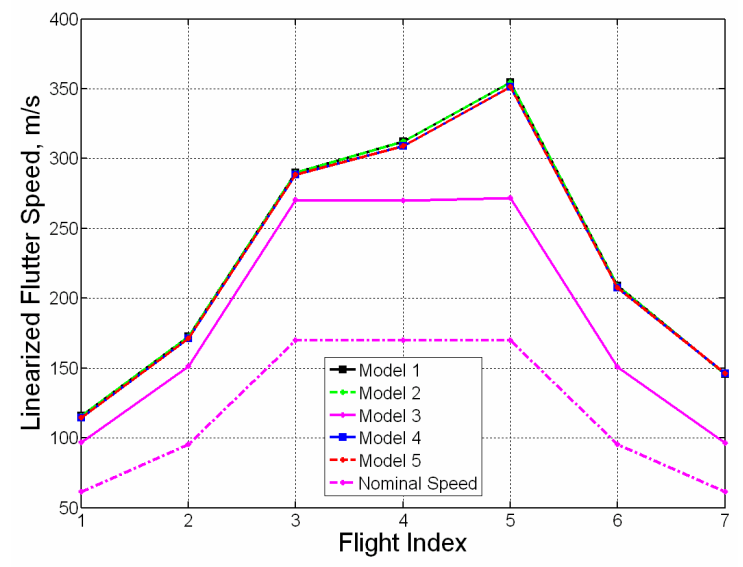

Figure 20. Flutter (unstable) speed at each flight index for different models of single-wing configuration.

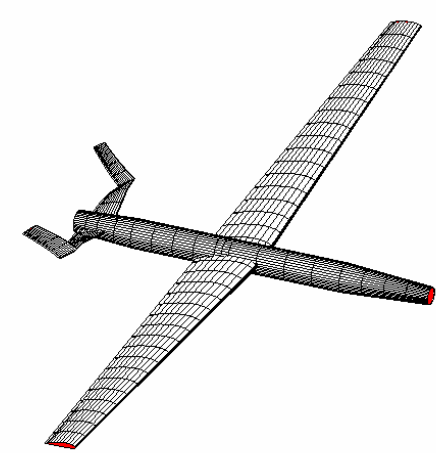

Flutter Speed: $270.31 \mathrm{~m} / \mathrm{s}$; Frequency: $2.91 \mathrm{HZ}$

Figure 21. Symmetric flutter (unstable) mode of single-wing configuration (Model 3, Index 3).

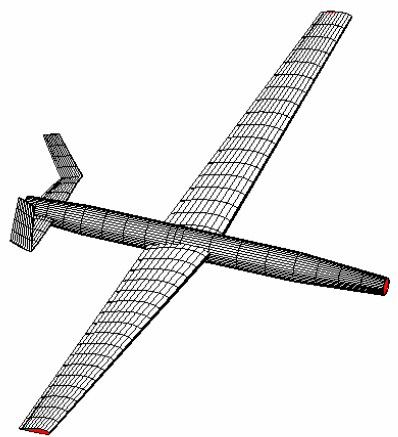

Flutter Speed: $271.63 \mathrm{~m} / \mathrm{s}$; Frequency: $2.91 \mathrm{HZ}$

Figure 22. Anti-symmetric flutter (unstable) mode of single-wing configuration (Model 3, Index 5). 


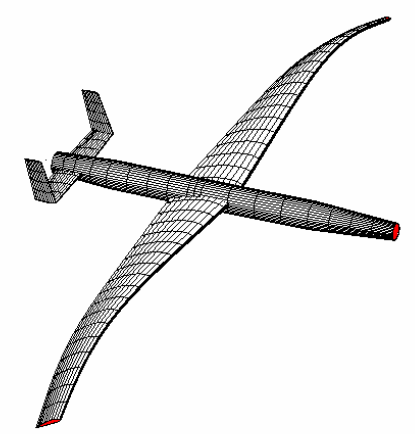

Flutter Speed: $288.48 \mathrm{~m} / \mathrm{s}$; Frequency: $3.14 \mathrm{HZ}$

Figure 23. Symmetric flutter (unstable) mode of single-wing configuration (Model 5, Index 3).

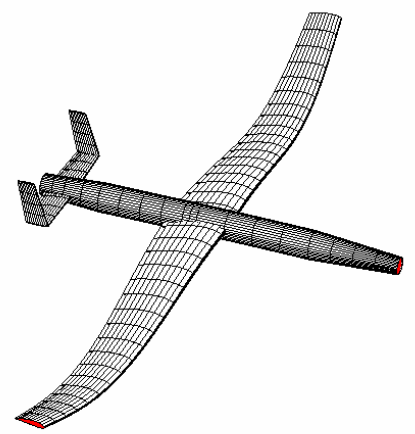

Flutter Speed: 351.29 m/s; Frequency: $4.00 \mathrm{HZ}$

Figure 24. Symmetric flutter (unstable) mode of single-wing configuration (Model 5, Index 5).

For the joined-wing configuration, the induced flexibility of the fuselage and vertical tail on the flutter speed is prominent as indicated in Fig. 25. Sample of the flutter modes are depicted in Figs. 26 to 33. Models 2, 3 and 4 seem to keep the same corresponding flutter mode throughout the different flight indices. Model 2 is purely wing flutter (anti-symmetric mode). Model 4 presents a symmetric flutter mode with vertical bending contribution of the fuselage, which reduces the flutter speed in comparison with Model 2. Model 3 presents an anti-symmetric flutter mode enabled by the lateral bending of the tail. Model 5 (fully flexible vehicle), however, shows a change in the flutter mode shape with flight index. At flight index 3, it presents an anti-symmetric flutter mode with contribution of both lateral bending of the vertical tail and lateral bending of the fuselage. At index 5, the flutter mode switches to be a symmetric one, similar to Model 4.

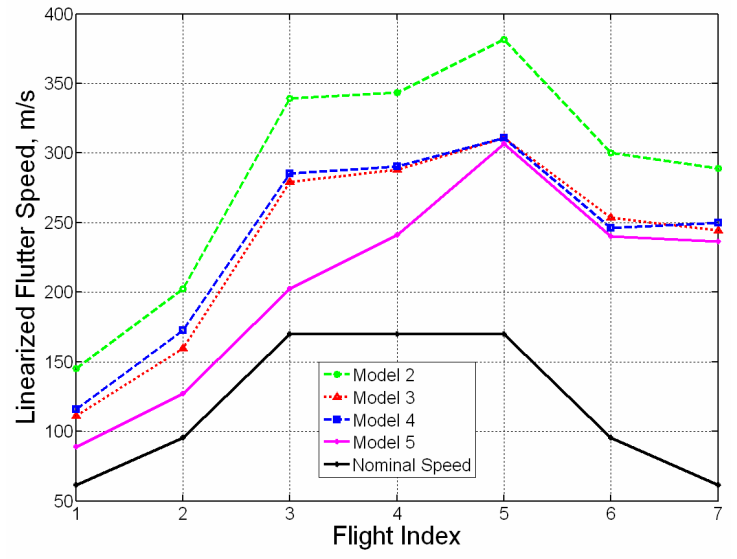

Figure 25. Flutter (unstable) speed at each flight index for different models of joined-wing configuration.

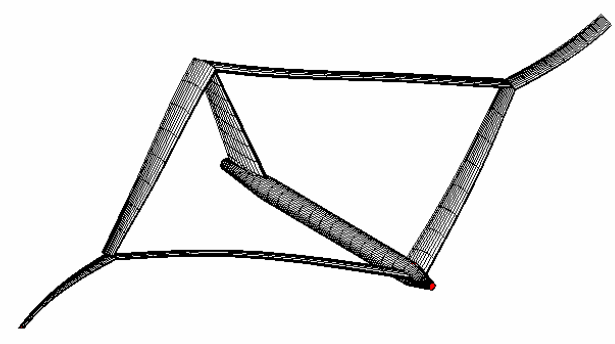

Flutter Speed: $339.34 \mathrm{~m} / \mathrm{s}$; Frequency: $0.94 \mathrm{HZ}$

Figure 26. Anti-symmetric flutter (unstable) mode of joined-wing configuration (Model 2, Index 3).

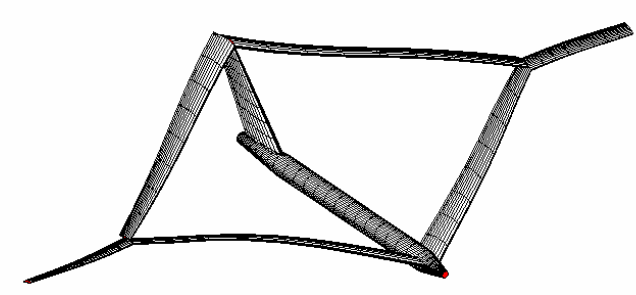

Flutter Speed: 381.66 m/s; Frequency: $2.29 \mathrm{HZ}$

Figure 27. Anti-symmetric flutter (unstable) mode of joined-wing configuration (Model 2, Index 5). 


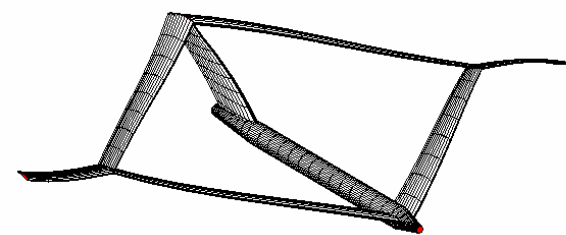

Flutter Speed: $279.20 \mathrm{~m} / \mathrm{s}$; Frequency: $0.97 \mathrm{HZ}$

Figure 28. Anti-symmetric flutter (unstable) mode of joined-wing configuration (Model 3, Index 3).

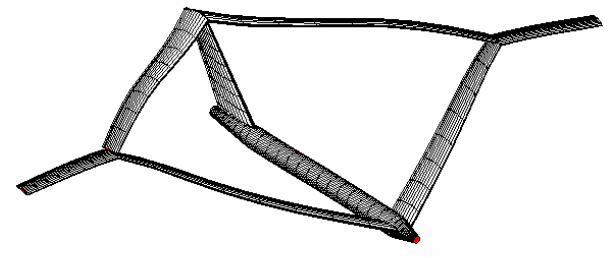

Flutter Speed: $285.36 \mathrm{~m} / \mathrm{s}$; Frequency: $0.96 \mathrm{HZ}$

Figure 30. Symmetric flutter (unstable) mode of joined-wing configuration (Model 4, Index 3).

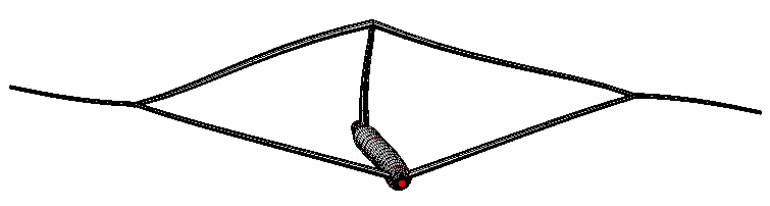

Flutter Speed: 202.54 m/s; Frequency: $0.63 \mathrm{HZ}$

Figure 32. Anti-symmetric flutter (unstable) mode of joined-wing configuration (Model 5, Index 3).

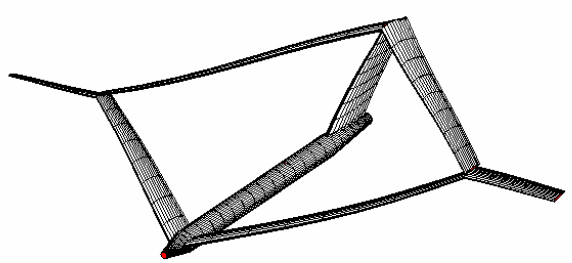

Flutter Speed: 310.82 m/s; Frequency: $2.32 \mathrm{HZ}$

Figure 29. Anti-symmetric flutter (unstable) mode of joined-wing configuration (Model 3, Index 5).

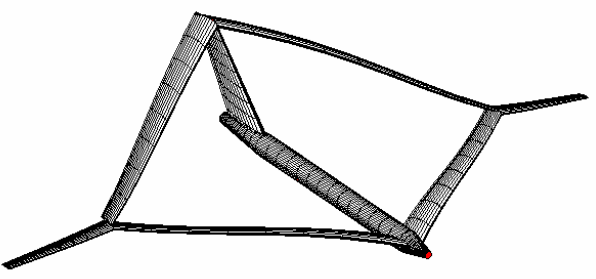

Flutter Speed: $311.05 \mathrm{~m} / \mathrm{s}$; Frequency: $2.11 \mathrm{HZ}$

Figure 31. Symmetric flutter (unstable) mode of joined-wing configuration (Model 4, Index 5).

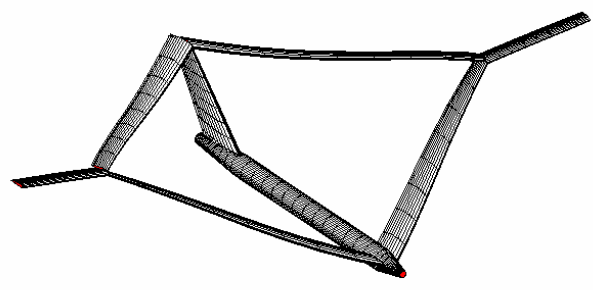

Flutter Speed: $306.58 \mathrm{~m} / \mathrm{s}$; Frequency: $2.08 \mathrm{HZ}$

Figure 33. Symmetric flutter (unstable) mode of joined-wing configuration (Model 5, Index 5).

\section{E. Static Stability}

Since the aft wings of a joined-wing aircraft are subject to compressive loads, their buckling response can be a sizing limitation for the vehicle. For the particular baseline designs considered here, deformation of the aft wing increases dramatically when the load factor reaches about 1.60, bringing the whole wing system close to a collapse. This is illustrated in Fig. 34 as the flight speed is increased at level flight (no retrimming). Note that this condition is naturally modeled in the presented framework through the nonlinear structural analysis. 

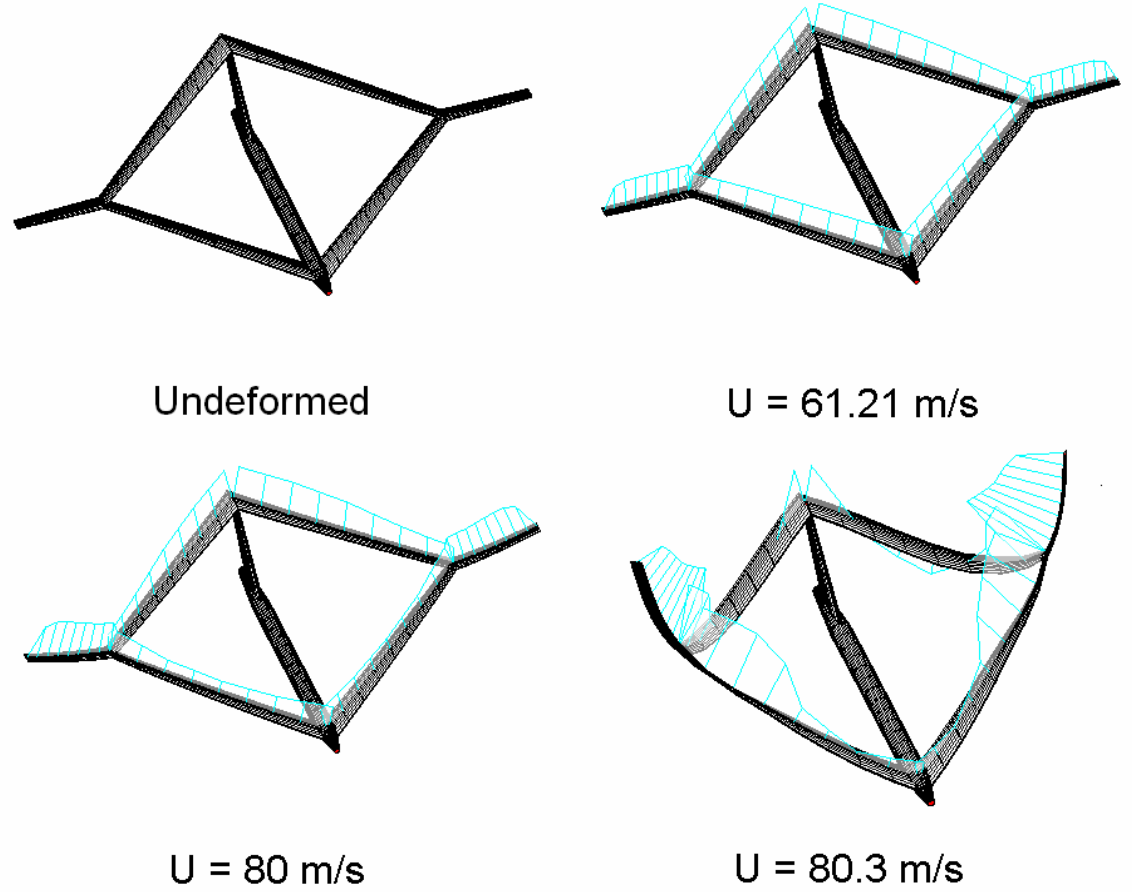

Figure 34. Lift distribution on the vehicle as the buckling speed is approached (sea level, fully fueled, no rigid body degrees of freedom, zero body angle of attack).

To study the effects of the flexibility from different members of the aircraft on the loss of static stability of the wings, Models 2 to 5 are brought to steady state at level flight (at sea level). Then, their flight speeds are varied from the nominal flight speed, which is $61.21 \mathrm{~m} / \mathrm{s}$, until there is a sudden drop in the lift generation capacity. This results in load factors ranging from 1.00 to approximately 1.60, depending on the model. The wing shape and deflections of the fully flexible model (Model 5) are plotted for varying load factor in Figs. 35 and 36. The corresponding tip positions versus flight speed and load factor are shown in Fig. 37. The suddenly reduction of the aft wing stiffness results in large bending deflection of the overall wing structure and, consequently, drop in the overall lift (represented by the reduction in load factor as shown in Fig. 37. This level of wing displacement causes high composite ply strains (stresses), to the point of ply failure. Strain components dependence on the load factor is shown in Figs. 38 to 40.

This static instability speed may vary because of different levels of flexibility of the vehicle (Table 4). The load factors, whose suddenly reduction indicates the onset of instability, are plotted as function of flight speed for different models, as shown in Fig 41. The model with a flexible vertical tail has the highest buckling speed, whereas the one with flexible fuselage has the lowest buckling speed. If one looks closer to the modes of deformation ("buckling mode"), they show a complex interaction between the vertical bending of the fuselage (particularly at the front wing connecting region) and the in-plane bending of the tail. These induced a change in the overall aerodynamic loading of the different wing segments, influencing the compressive load applied to the aft wing. Since the different models were only trimmed at the point corresponding to load factor 1 in Fig. 41, the other load factor points may represent a very different solution in terms of vehicle c.g. forces and moments. Further studies are needed to better understand the implications of the flexibility of the fuselage and vertical tail on the static instability of the vehicle. 


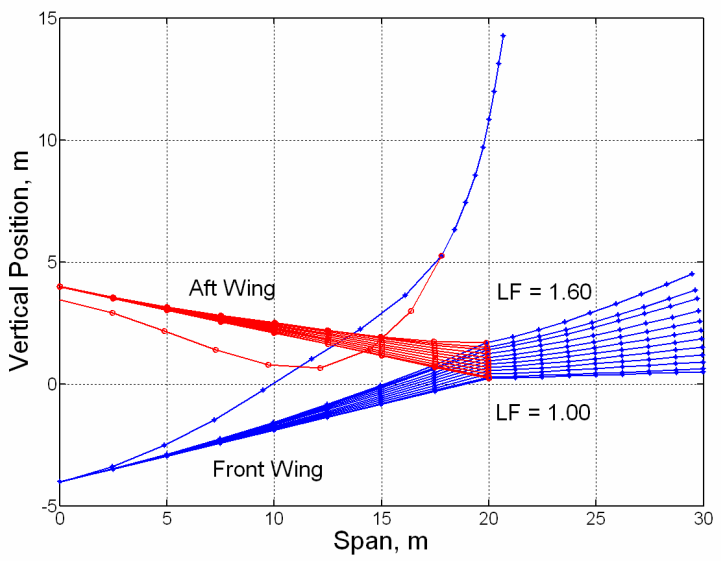

Figure 35. Wing shape for varying flight speed (level flight at sea level).

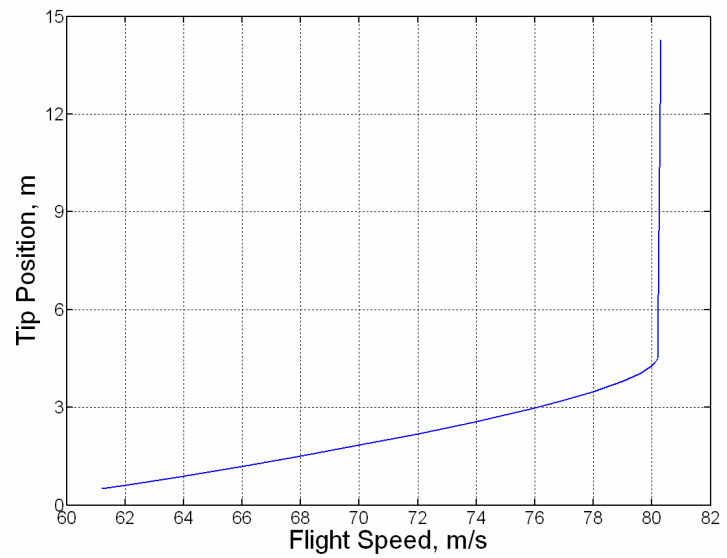

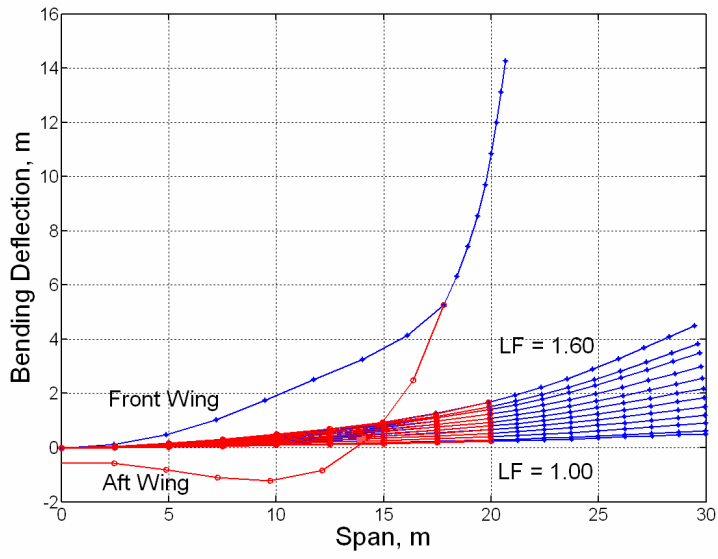

Figure 36. Wing bending deflections for varying flight speed (level flight at sea level).

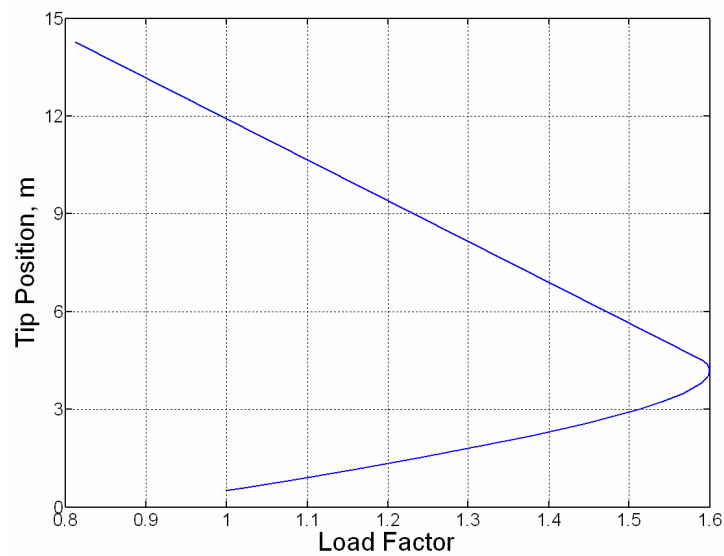

Figure 37. Changes in tip deflection as function of the lift generation capability of the vehicle at level flight (sea level).

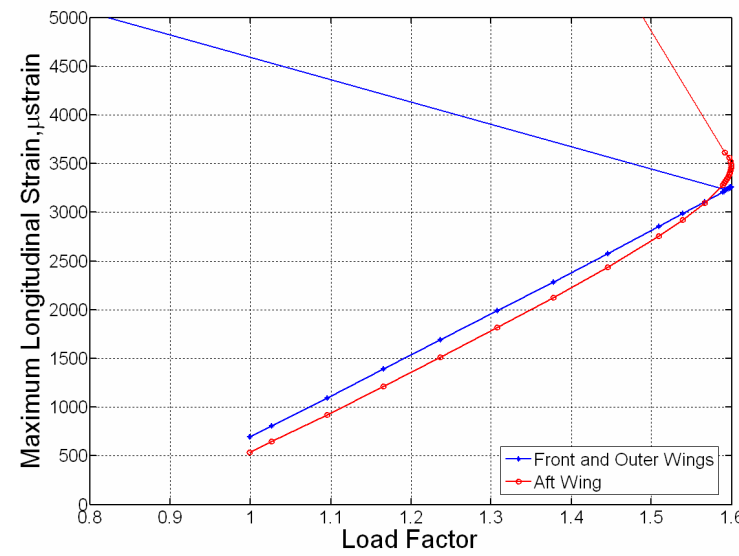

Figure 38. Maximum longitudinal strain component nonlinear growth due to loss of stiffness on the aft wing with increase load factor (level flight, sea level).

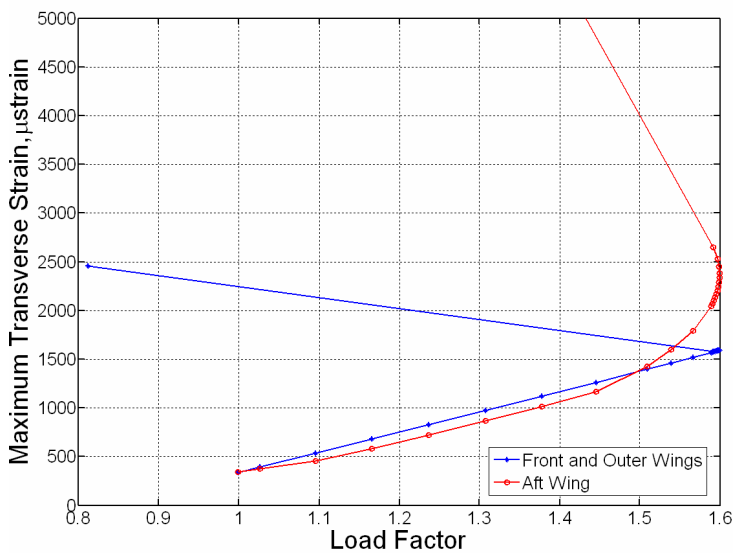

Figure 39. Maximum transverse strain component nonlinear growth due to loss of stiffness on the aft wing with increase load factor (level flight, sea level). 


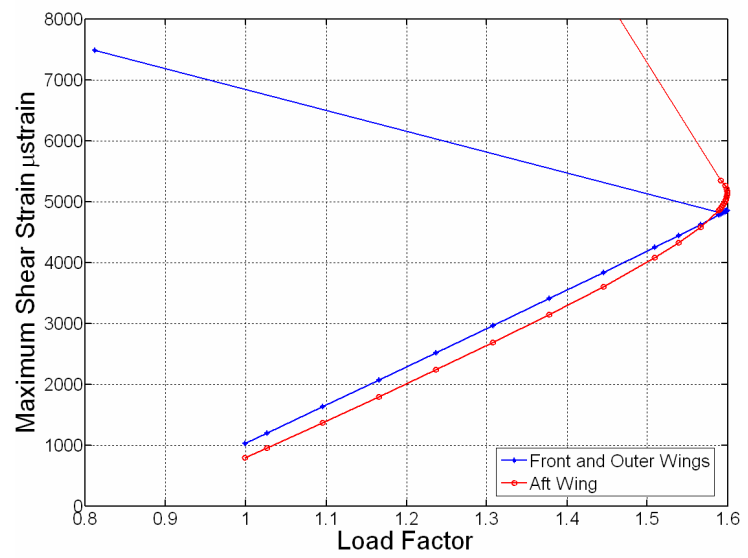

Figure 40. Maximum shear strain component nonlinear growth due to loss of stiffness on the aft wing with increase load factor (level flight, sea level).

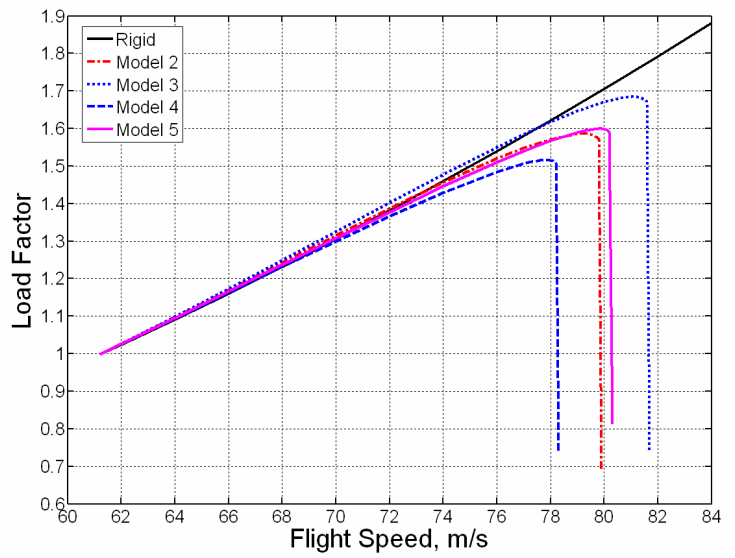

Figure 41. Load fact with respect to flight speeds for different models of joined-wing configuration (level flight, sea level).

\section{Concluding Remarks}

This paper presented a nonlinear aeroelastic formulation for the modeling and analysis not only of the very flexible wings but also their coupling with flexible fuselage and tail. The geometrically-nonlinear structural model is a strain-based formulation able to capture the large deformations in slender composite structures. The unsteady aerodynamics is incompressible, and written in space-state form. The low-order aeroelastic framework is intended for preliminary design and assessment of aeroelastic response and its coupling with flight dynamics of very flexible aircraft. The low-order representation of the fully flexible vehicle is to be used for control design.

Based on the new approach, two of the three aircraft configurations being considered for the Sensorcraft program were studied: single-wing and joined-wing configurations. Specifically, the paper presented the effects of the added flexibility of the fuselage and tail to the very flexible wings in the roll response, onset of flutter, and static ("buckling-like") instability (for joined-wing only).

From the results of the numerical studies, it is clear that joined-wing configurations present much richer and complex aeroelastic characteristics than single-wing ones. The modeled joined-wing vehicle is more susceptible to the induced flexibility of the fuselage and tail in terms of roll performance, where there can be a significant reduction in roll angle as function of time due to the added flexibility. As for the linearized flutter speed, flexible fuselage and vertical tail both reduces the flutter speed of joined-wing configuration, whereas the flexibility of the fuselage and tail of the single-wing configuration does not significantly impacts the wing flutter (unless the wing flutters first). Regarding the unique problem of loss of stiffness in the aft wing in the joined-wing configuration, preliminary results indicated that the added flexible fuselage decreases "buckling" speed, while adding the flexibility of the vertical tail increases it. More studies are needed to better understand those relative effects. 
While the proposed framework has been created to handle any structural configuration made of slender (active) composite components (wings, tails, fuselages), in its current form it cannot properly handle the flexibility of the body in a wing-body configuration (third Sensorcraft concept being considered). Current work is under way to extend the framework to bring non-slender flexible bodies to be coupled with the present nonlinear aeroelastic formulation.

\section{Acknowledgment}

This work has been sponsored by AFOSR grant F49620-02-1-0425. The technical monitor is Dr. Clark Allred, Capt. USAF.

\section{References}

${ }^{1}$ Patil, M. J., Hodges, D. H., and Cesnik, C. E. S., "Nonlinear Aeroelasticity and Flight Dynamics of High-Altitude Long Endurance Aircraft," Journal of Aircraft. Vol. 38, No. 1 Jan. - Feb. 2001.

${ }^{2}$ Van Shoor, M. C., Zerweckh, S. H. and von Flotow, A. H., "Aeroelastic Stability and Control of a Highly Flexible Aircraft", AIAA Paper, AIAA-89-1187-CP, 1989.

${ }^{3}$ Drela, M., "Integrated Simulation Model for Preliminary Aerodynamic, Structural, and Control-Law Design of Aircraft", AIAA Paper, AIAA-99-1394, 1999.

${ }^{4}$ Tilmann, C. P., Flick, P. M., Martin, C. A., and Love, M. H., "High-Altitude Long Endurance Technologies for SensorCraft," RTO AVT Symposium on Novel and Emerging Vehicle and Vehicle Technology Concepts. Brussels, Belgium, April 2003. RTO Paper MP-104-P-26.

${ }^{5}$ Wolkovitch, J., “The Joined Wing: An Overview”, Journal of Aircraft. Vol. 23, No. 3, 1996, pp. 161-178.

${ }^{6}$ Livne, E., "Aeroelasticity of Joined-Wing Airplane configurations: Past Work and Future Challenges - a Survey", AIAA Paper AIAA-2001-1370, AIAA/ASME/ASCE/AHS 42nd Structures, Structural Dynamics, and Materials Conference, Seattle, WA, 16-19 April 2001.

${ }^{7}$ Lin, H.-H., Jhou, J., and Stearman, R., "Influence of Joint Fixity on the Aeroelastic Characteristics of a Joined Wing Structure," AIAA-90-0980-CP, pp. 1442-1454, 1990

${ }^{8}$ Samuels, M. F., "Structural Weight Comparison of a Joined Wing and a Conventional Wing", Journal of Aircraft. June 1982 , pp. 485-491.

${ }^{9}$ Gallman, J.W. and Kroo, I.M., "Structural Optimization for Joined-Wing Synthesis", Journal of Aircraft. Vol. 33, No. 1, Jan-Feb 1996, pp. 214-223.

${ }^{10}$ Miural, H., Shyu, A. T., and Wolkovitch, J., "Parameter Weight Evaluation of Joined Wing by Structural Optimization", AIAA Paper 85-0642, AIAA/ASME/ASCE/AHS 26th Structures, Structural Dynamics, and Materials Conference, Orlando, FL, April 1985.

${ }^{11}$ Blair, M. and Canfield, R. A., “A Joined-Wing Structural Weight Modeling Study”, AIAA Paper, AIAA-2002-1337, 2002.

${ }^{12}$ Kroo, I.M., Gallman, J.W. and Smith, S.C., "Aerodynamic and Structural Studies of Joined-Wing Aircraft" Journal of Aircraft. Vol. 28, No. 1, 1991, pp. 74-81.

${ }^{13}$ Gallman, J.W. and Smith, S.C., "Optimization of Joined Wing Aircraft", Journal of Aircraft. Vol. 30, No. 6, Nov-Dec 1993, pp. 897-965.

${ }^{14}$ Roberts, R.W. Jr., Canfield, R.A. and Blair, M., "Sensor-Craft Structural Optimization and Analytical Certification", AIAA Paper AIAA-2003-1458, AIAA/ASME/ASCE/AHS 44th Structures, Structural Dynamics, and Materials Conference. Norfolk, VA, 7-10 April 2003.

${ }^{15}$ Rasmussen, C. C., Canfield, R. A. and Blair, M., "Optimization Process for Configuration of Flexible Joined-wing”, AIAA Paper AIAA-2004-4330, $10^{\text {th }}$ AIAA/ISSMO Multidisciplinary Analysis and Optimization Conference, August 30 - September 1, 2004, Albany, NY

${ }^{16}$ Reich, G.W., Raveh, D. and Zink, P.S., "Application of Active Aeroelastic Wing Technology to a Joined-Wing Sensorcraft”, AIAA Paper AIAA-2002-1633, 2002.

${ }^{17}$ Cesnik, C. E. S. and Brown, E. L., "Active Warping Control of a Joined Wing Airplane Configuration," Proceedings of the 44th Structures, Structural Dynamics, and Material Conference, Hampton, Virginia, April 7 - 10, 2003.

${ }^{18}$ Brown, E. L., "Integrated Strain Actuation in Aircraft with Highly Flexible Composite Wings," Ph.D. Thesis, Mechanical Engineering, Massachusetts Institute of Technology, Cambridge, Massachusetts, June 2003.

${ }^{19}$ Peters, D. A. and Johnson, M. J., "Finite-State Airloads for Deformable Airfoils on Fixed and Rotating Wings", Symposium on Aeroelasticity and Fluid/Structure InteractionPreceedings of the Winter Annual Meeting, AD Vol. 44, American Society of Mechinal Engineers, Fairfield, NJ, 1994, pp.1-28.

\section{Appendix}

Single-wing Configuration Cross-sectional Property Distributions. The stiffness and inertia properties of each cross-section of the wing, tail and fuselage are shown in Figs A1 to A21. 


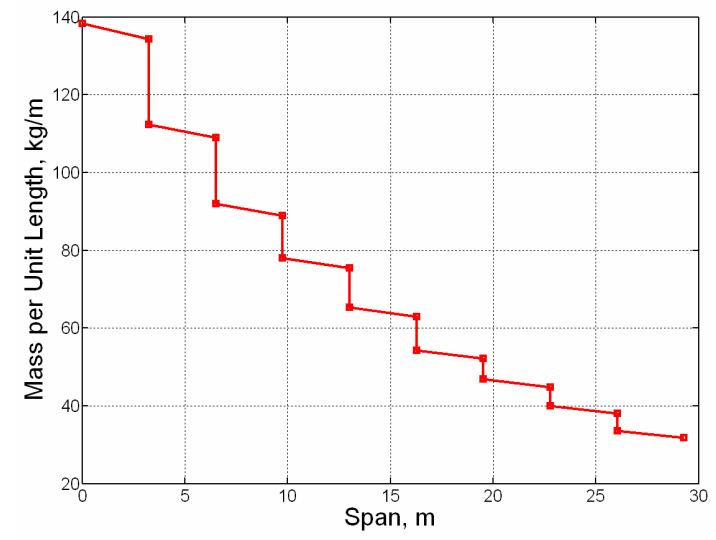

Figure A1. Wing spanwise mass distribution for single-wing configuration.

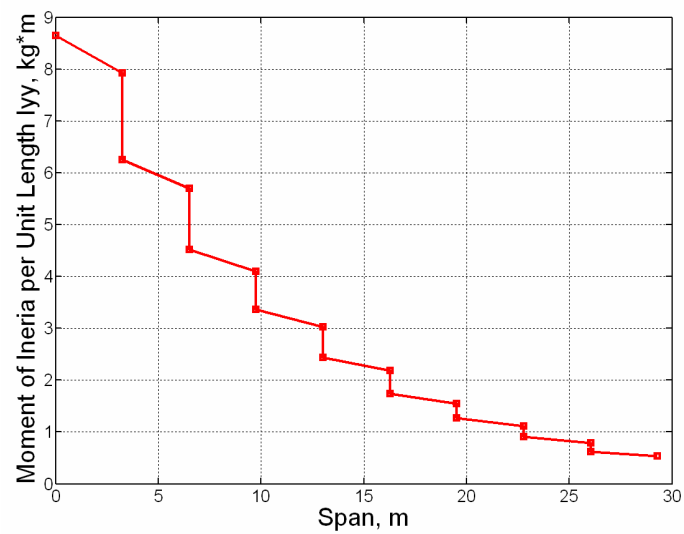

Figure A3. wing spanwise bending moment of inertia distribution (Iyy) for single-wing configuration.

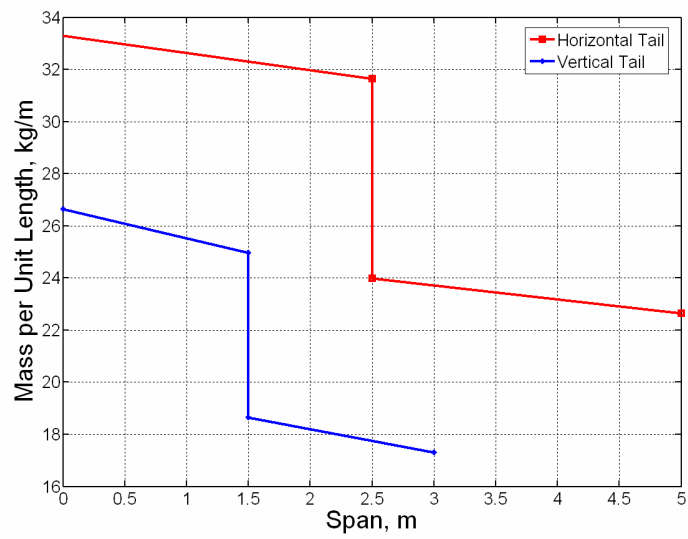

Figure A5. Tail spanwise mass distribution for single-wing configuration.

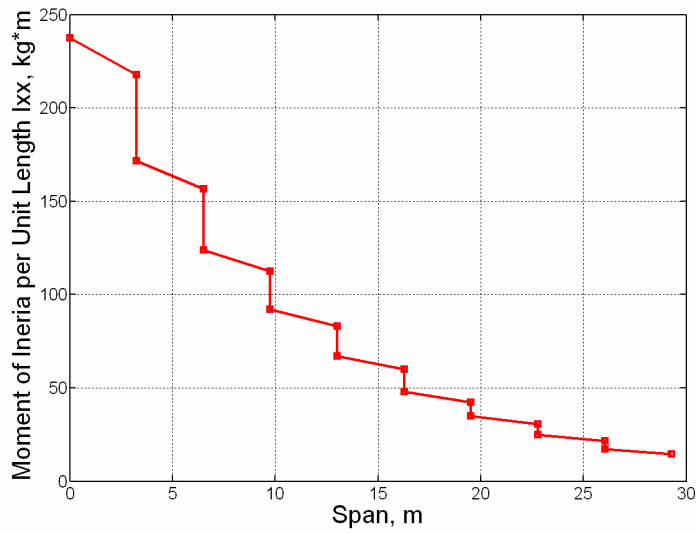

Figure A2. Wing panwise torsional moment of inertia distribution (Ixx) for single-wing configuration.

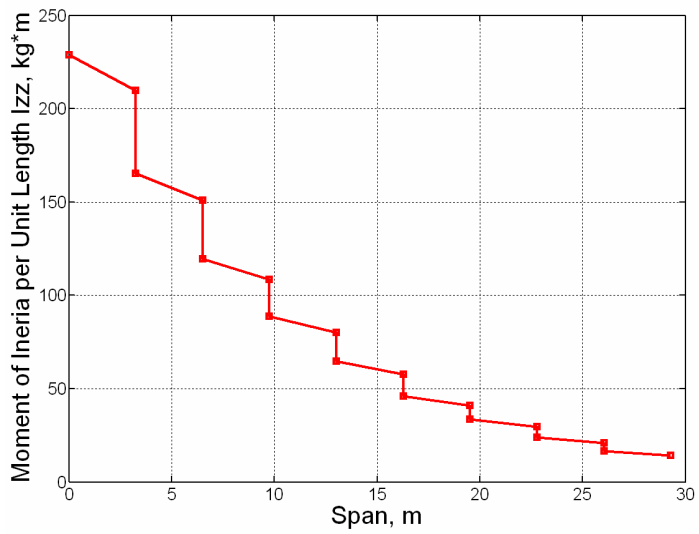

Figure A4. Wing spanwise chordwise bending moment of inertia distribution (Izz) for singlewing configuration.

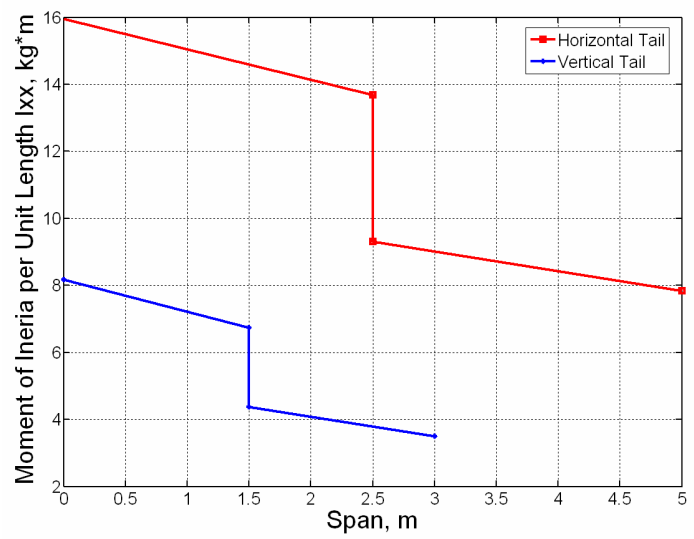

Figure A6. Tail spanwise torsional moment of inertia distribution (Ixx) for single-wing configuration. 


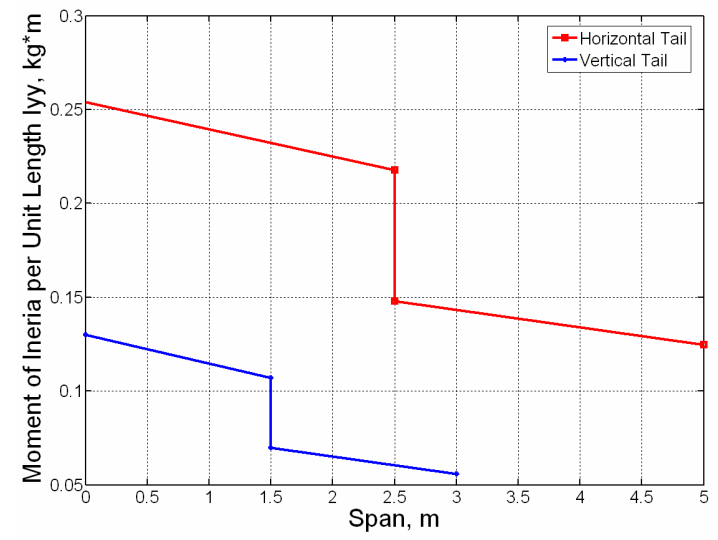

Figure A7. Tail spanwise bending moment of inertia distribution (Iyy) for single-wing configuration.

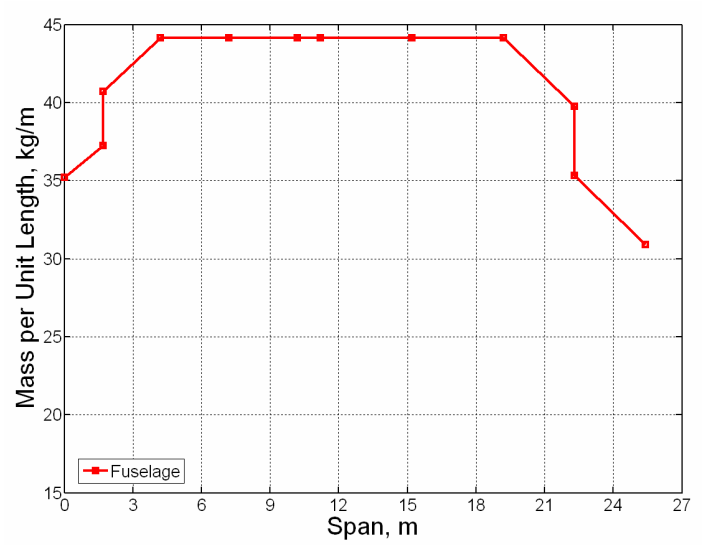

Figure A9. Fuselage spanwise mass distribution for single-wing configuration.

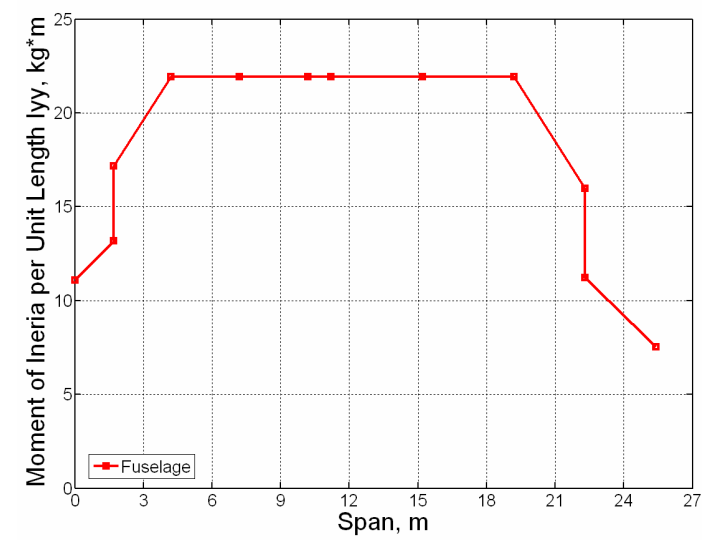

Figure A11. Fuselage spanwise bending moment of inertia distribution (Iyy) for singlewing configuration.

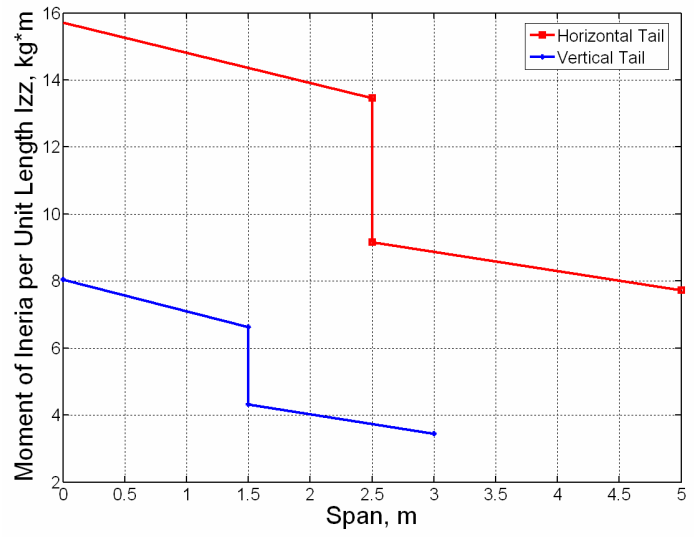

Figure A8. Tail spanwise chordwise bending moment of inertia distribution (Izz) for singlewing configuration.

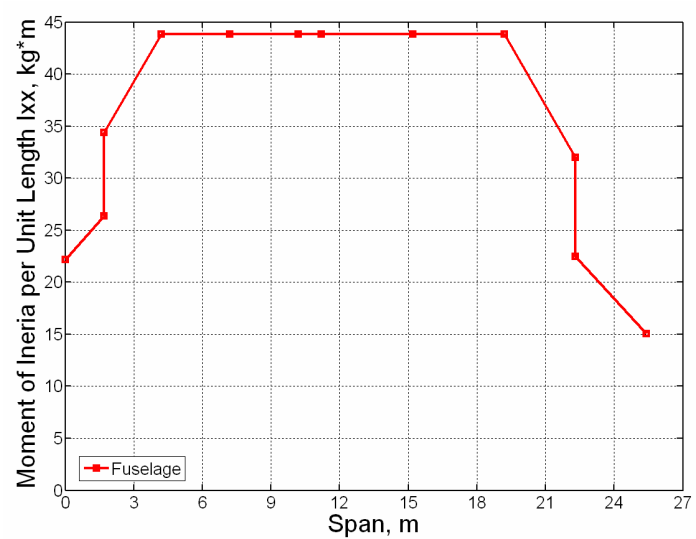

Figure A10. Fuselage spanwise torsional moment of inertia distribution (Ixx) for singlewing configuration.

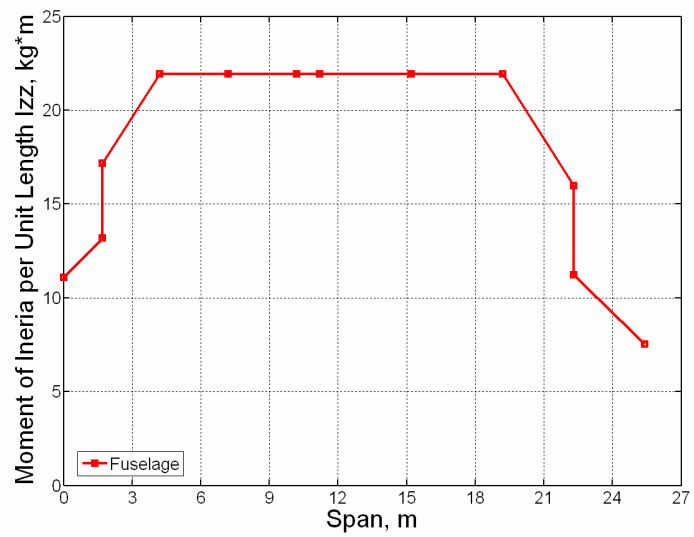

Figure A12. Fuselage spanwise chordwise bending moment of inertia distribution (Izz) for single-wing configuration. 


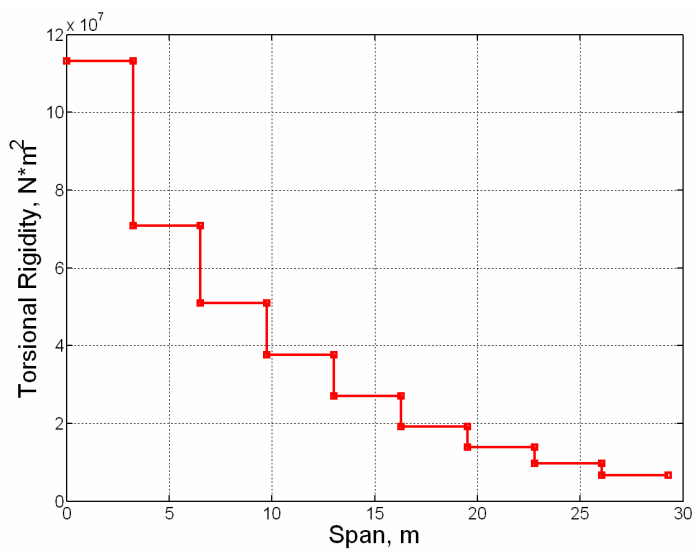

Figure A13. Wing spanwise torsional rigidity distribution for single-wing configuration.

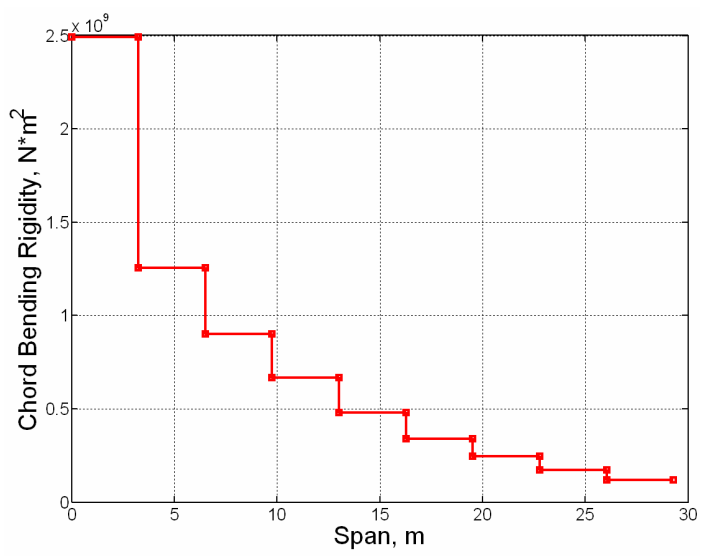

Figure A15. Wing spanwise chordbending rigidity distribution for single-wing configuration.

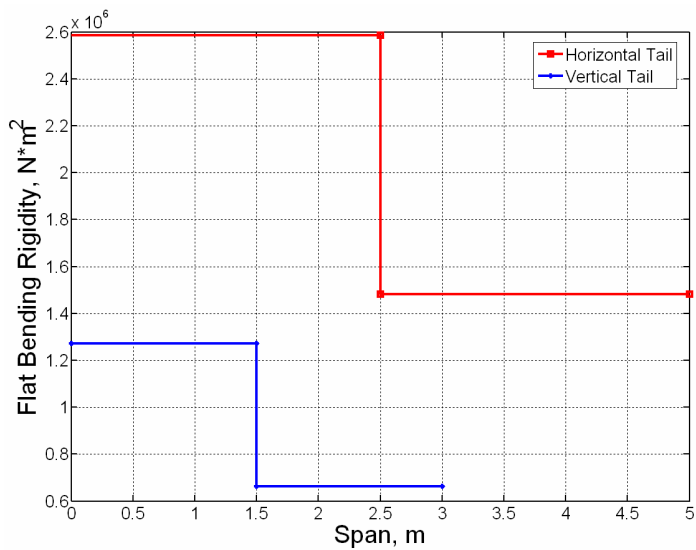

Figure A17. Tail spanwise flatbending rigidity distribution for single-wing configuration.

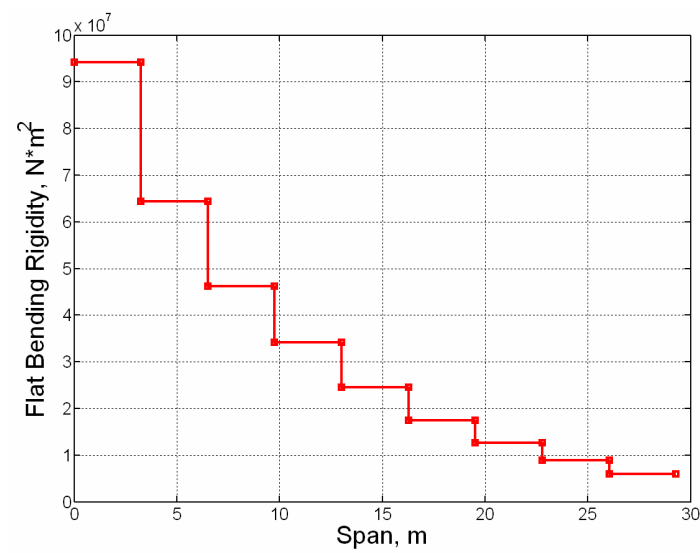

Figure A14. Wing spanwise flatbending rigidity distribution for single-wing configuration.

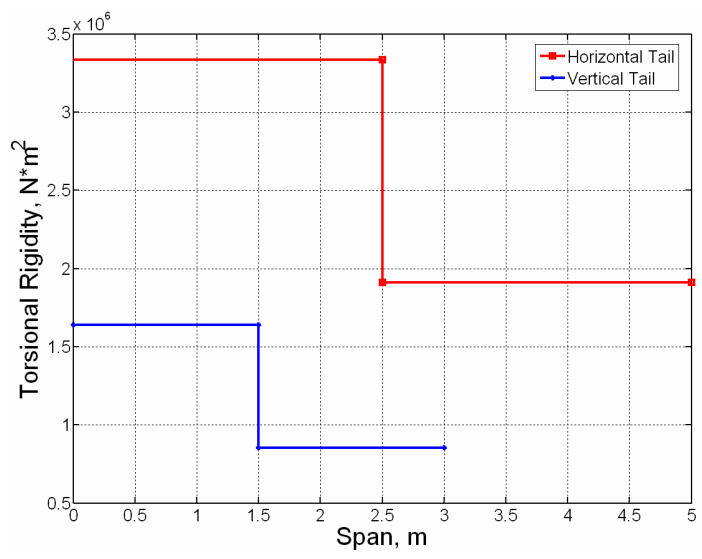

Figure A16. Tail spanwise torsional rigidity distribution for single-wing configuration.

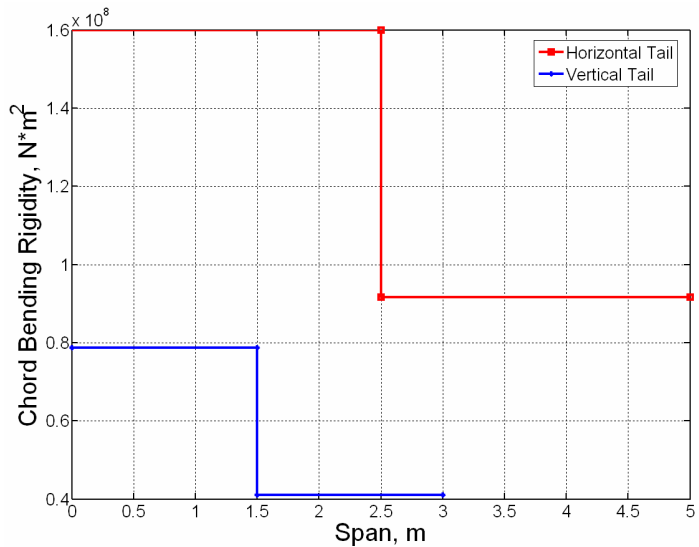

Figure A18. Tail spanwise chordbending rigidity distribution for single-wing configuration. 


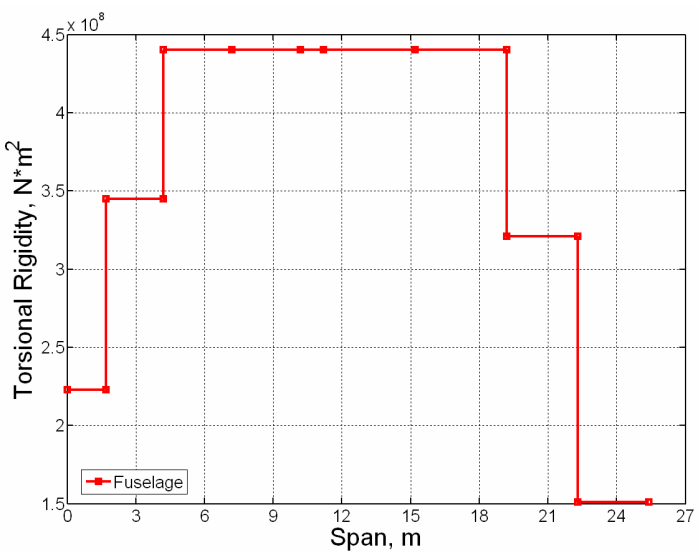

Figure A19. Fuselage spanwise torsional rigidity distribution for single-wing configuration.

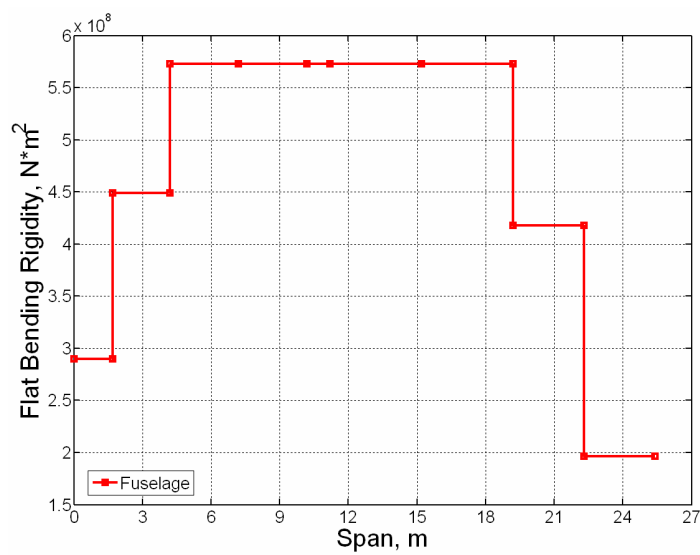

Figure A20. Fuselage spanwise flatbending rigidity distribution for single-wing configuration.

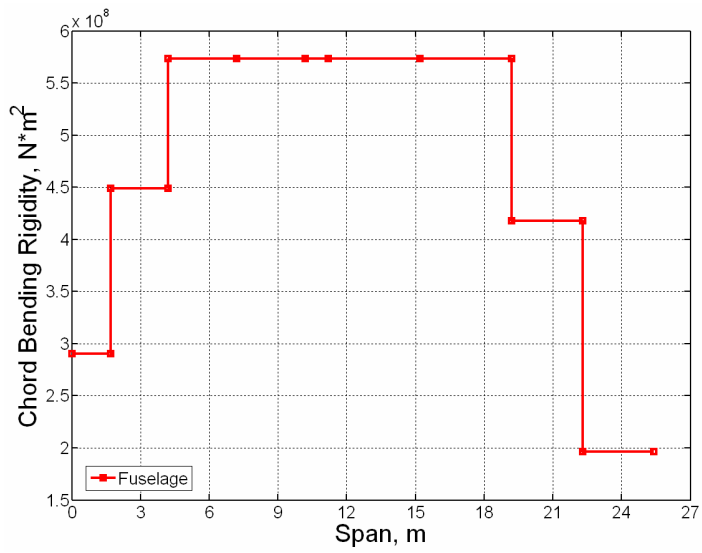

Figure A21. Fuselage spanwise chordbending rigidity distribution for single-wing configuration.

Joined-wing Configuration Cross-sectional Property Distributions. The stiffness and inertia properties of the wing, vertical tail and fuselage are shown in Figs. A22 to A42.

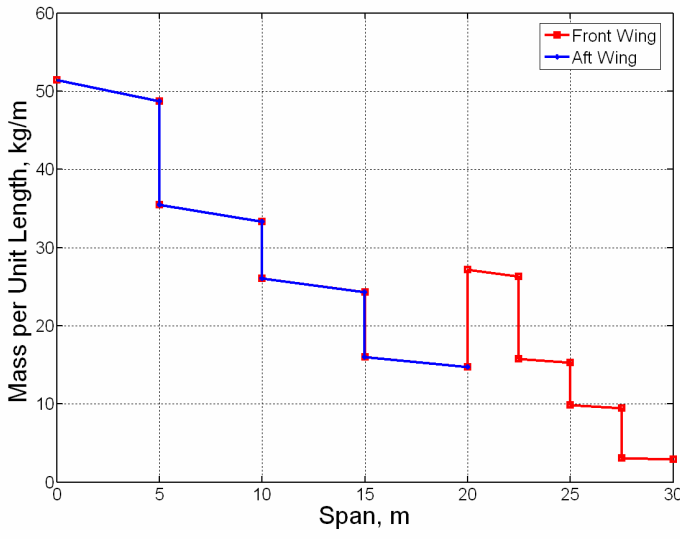

Figure A22. Wing spanwise mass distribution for joined-wing configuration.

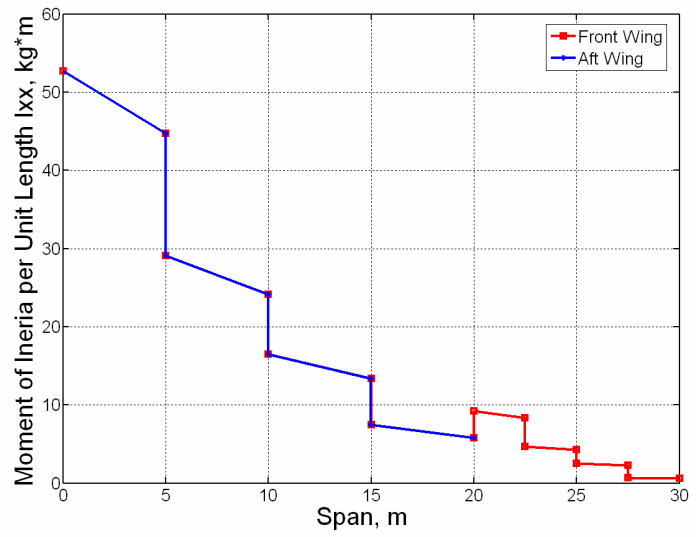

Figure A23. Wing spanwise torsional moment of inertia distribution (Ixx) for joined-wing configuration. 


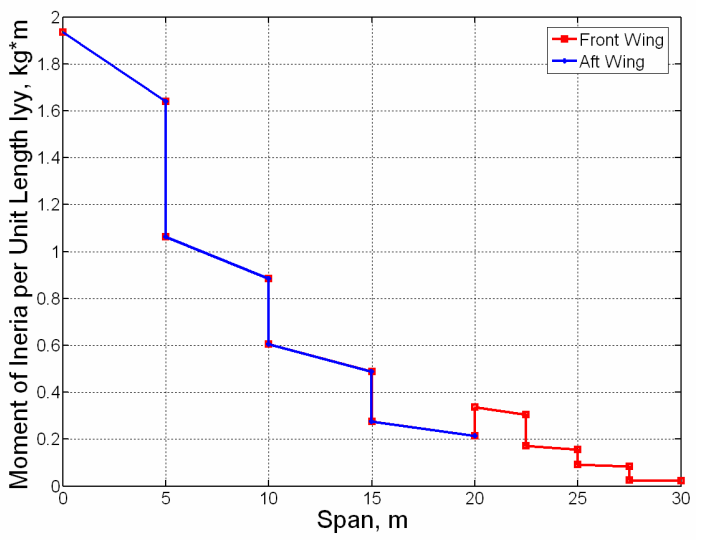

Figure A24. Wing spanwise bending moment of inertia distribution (Iyy) for joined-wing configuration.

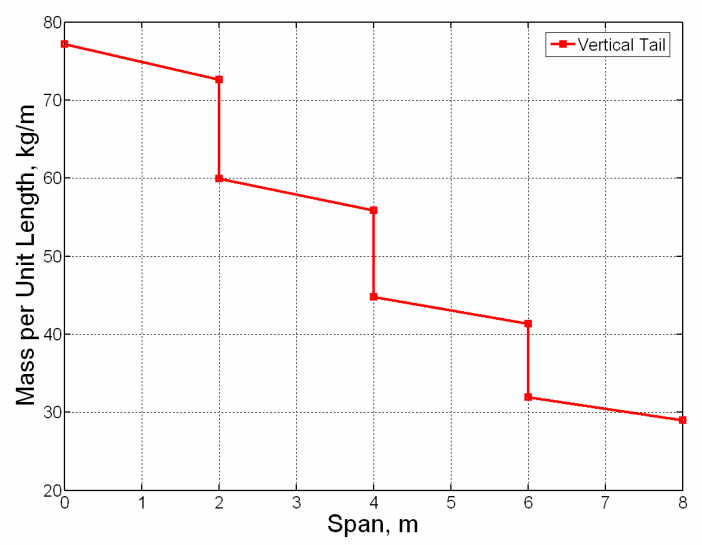

Figure A26. Vertical tail spanwise mass distribution for joined-wing configuration.

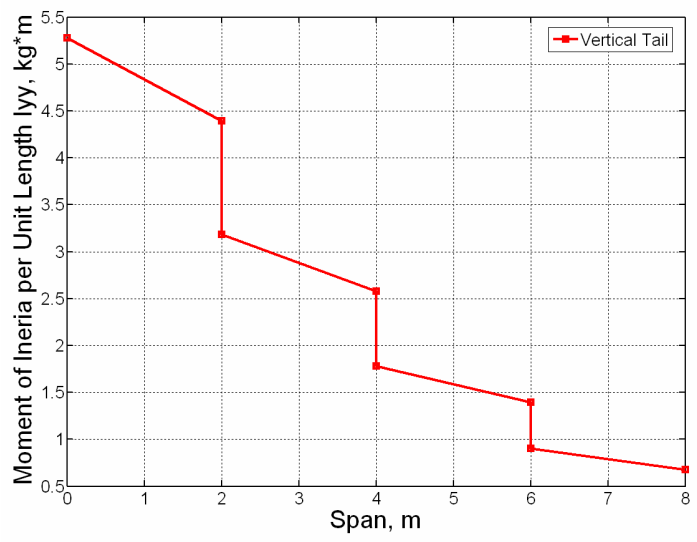

Figure A28. Vertical tail spanwise bending moment of inertia distribution (Iyy) for joinedwing configuration.

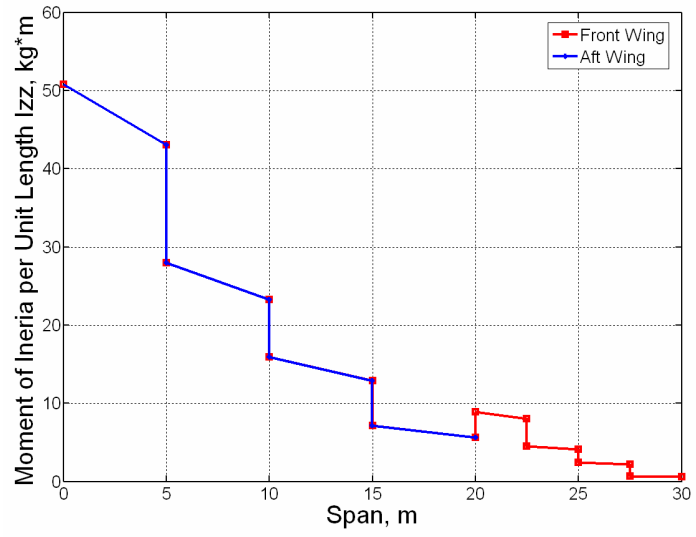

Figure A25. Wing spanwise chordwise bending moment of inertia distribution (Izz) for joinedwing configuration.

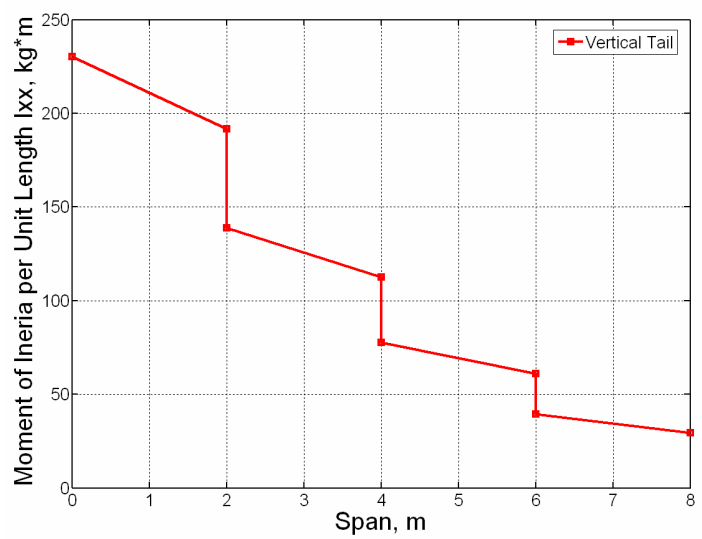

Figure A27. Vertical tail spanwise torsional moment of inertia distribution (Ixx) for joinedwing configuration.

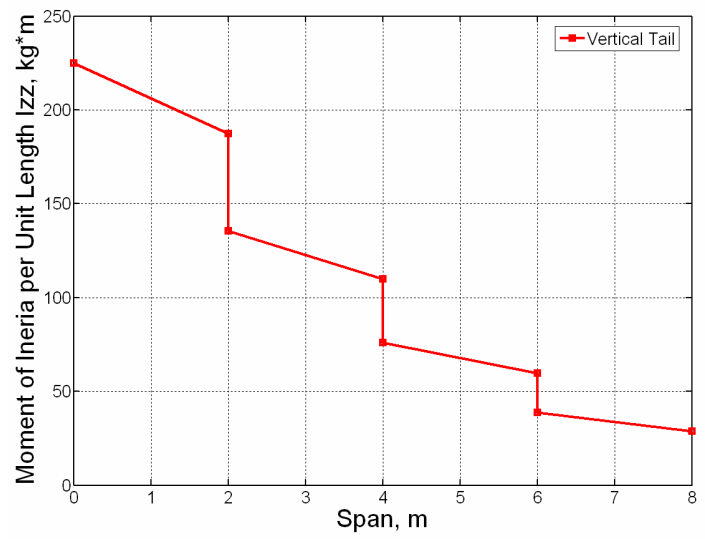

Figure A29. Vertical tail spanwise chordwise bending moment of inertia distribution (Izz) for joined-wing configuration. 


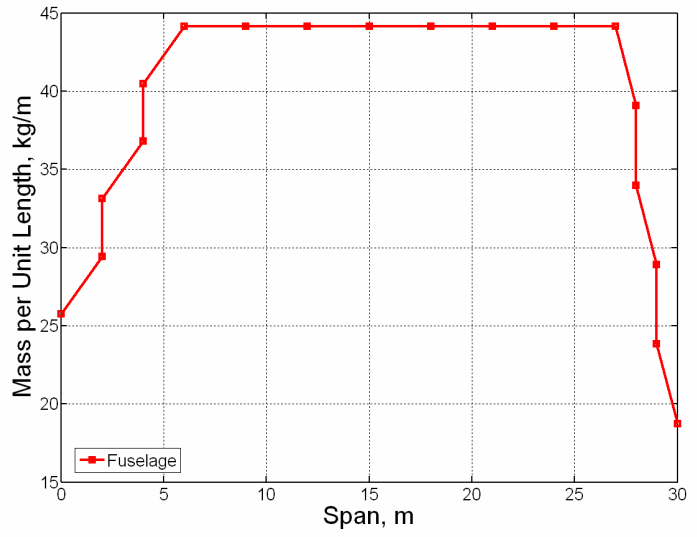

Figure A30. Fuselage spanwise mass distribution for joined-wing configuration.

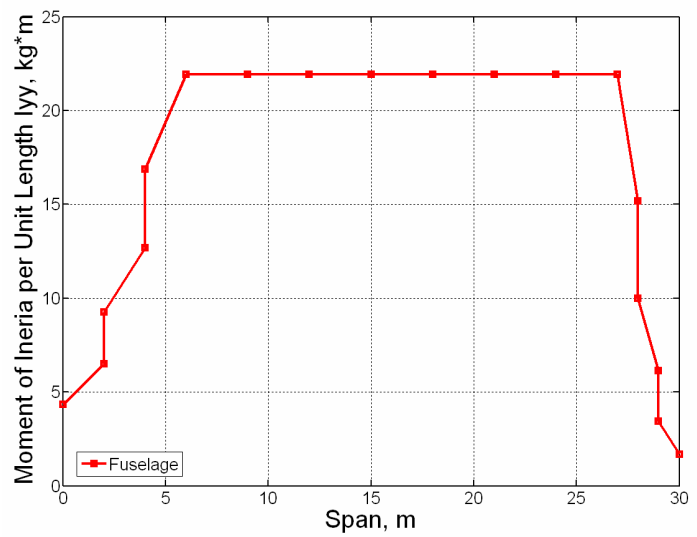

Figure A32. Fuselage spanwise bending moment of inertia distribution (Iyy) for joinedwing configuration.

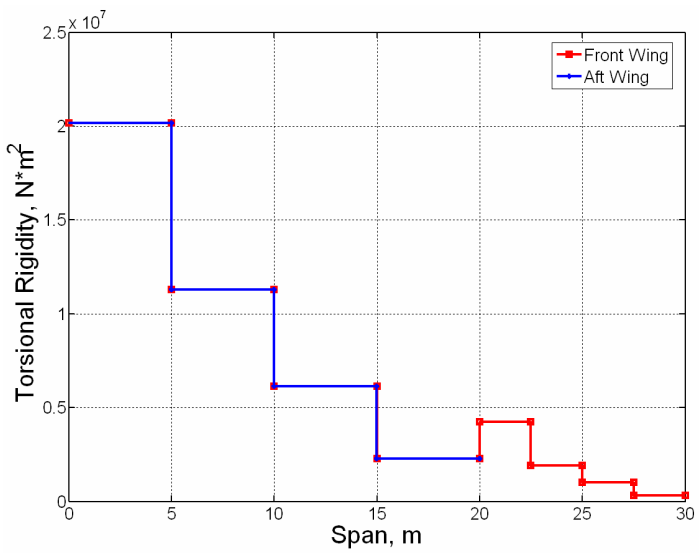

Figure A34. Wing spanwise torsional rigidity distribution for joined-wing configuration.

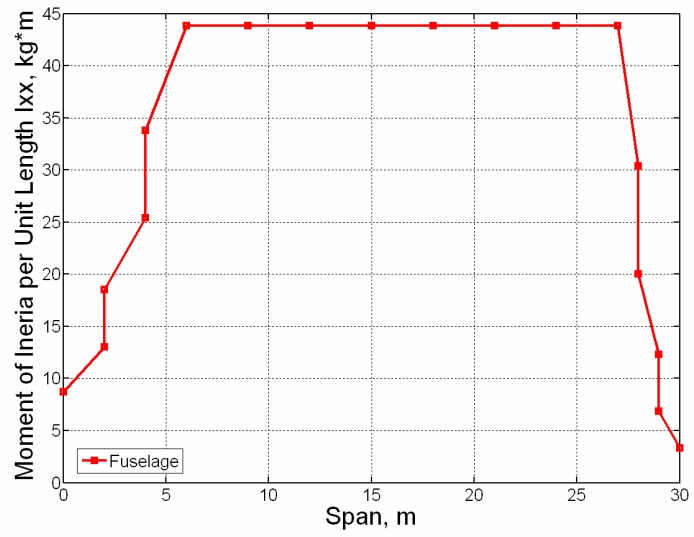

Figure A31. Fuselage spanwise torsional moment of inertia distribution (Ixx) for joined-wing configuration.

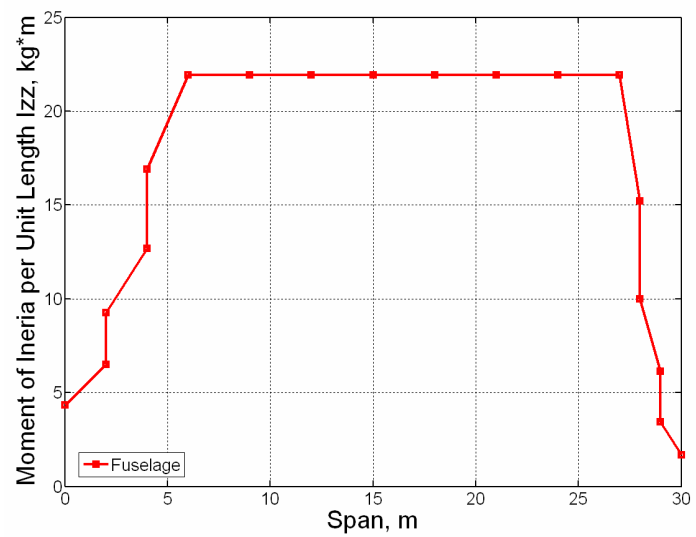

Figure A33. Fuselage spanwise chordwise bending moment of inertia distribution (Izz) for joined-wing configuration.

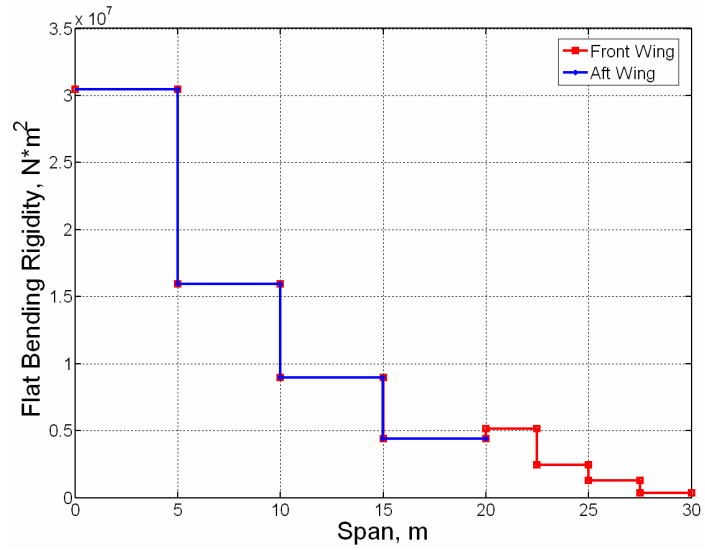

Figure A35. Wing spanwise flatbending rigidity distribution for joined-wing configuration. 


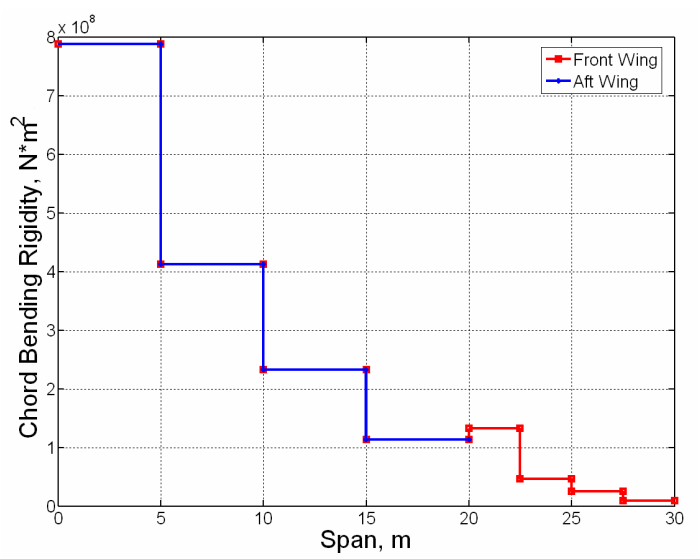

Figure A36. Wing spanwise chordbending rigidity distribution for joined-wing configuration.

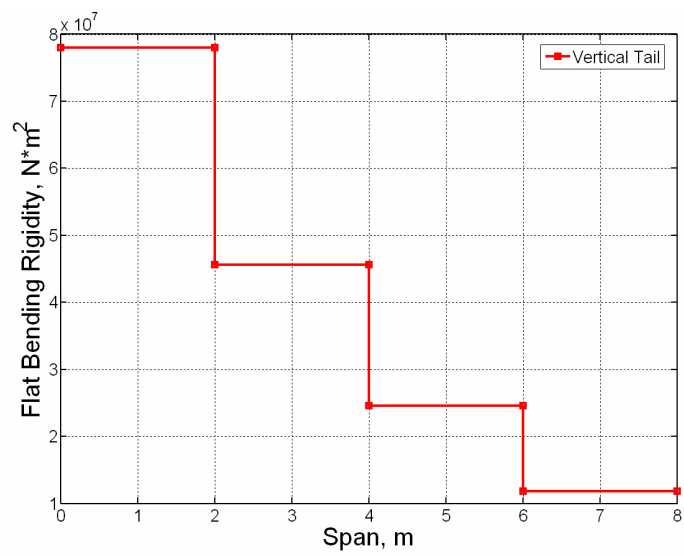

Figure A38. Vertical tail spanwise flatbending rigidity distribution for joined-wing configuration.

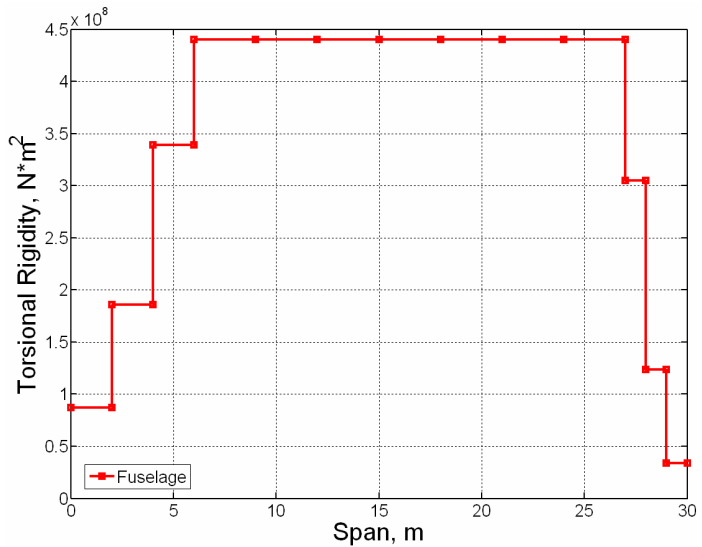

Figure A40. Fuselage spanwise torsional rigidity distribution for joined-wing configuration.

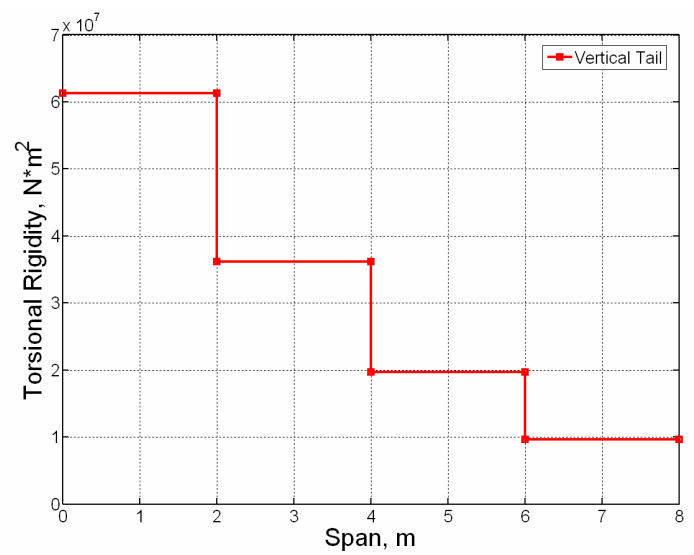

Figure A37. Vertical tail spanwise torsional rigidity distribution for joined-wing configuration.

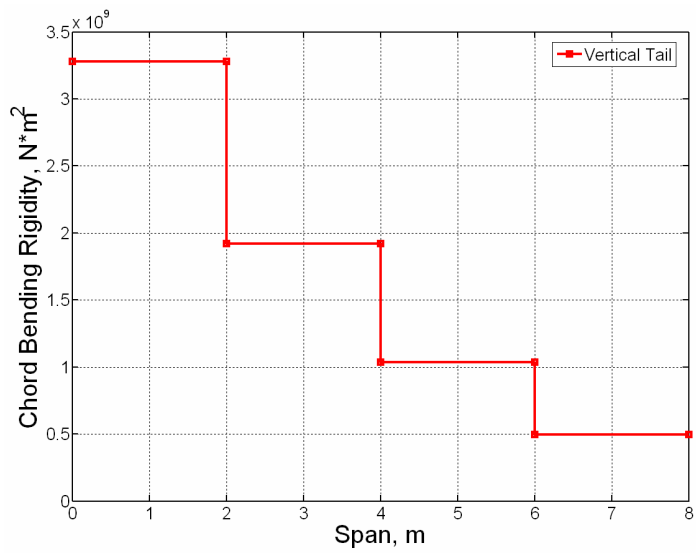

Figure A39. Vertical tail spanwise chordbending rigidity distribution for joined-wing configuration.

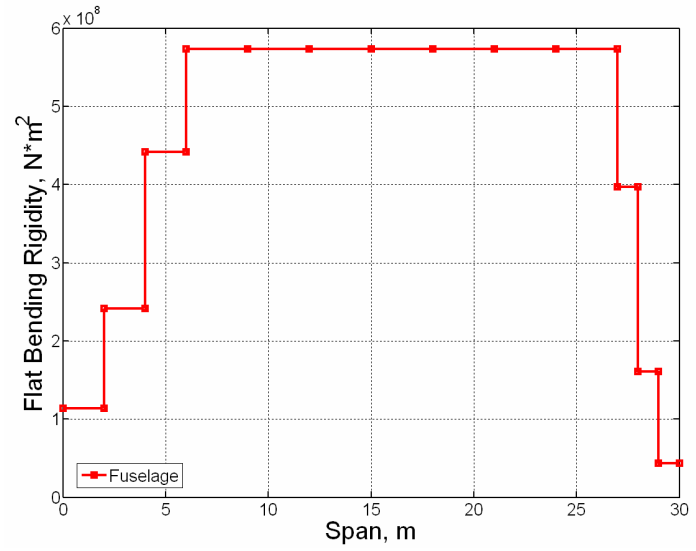

Figure A41. Fuselage spanwise flatbending rigidity distribution for joined-wing configuration. 


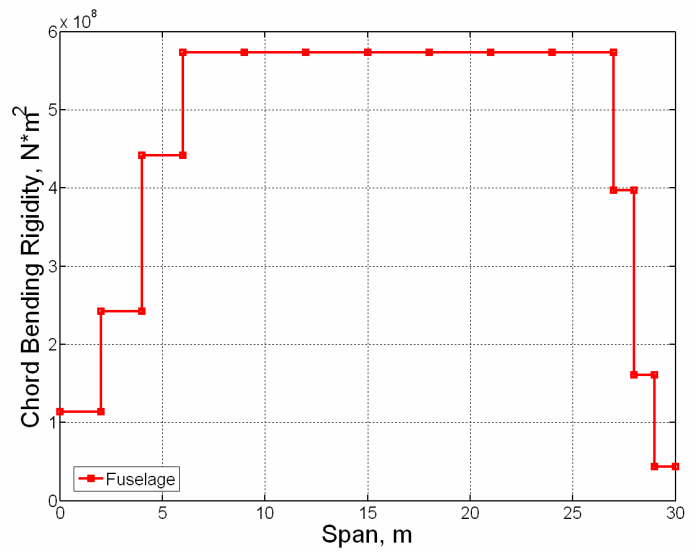

Figure A42. Fuselage spanwise chordbending rigidity distribution for joined-wing configuration. 